INDEPENDENT CONFIRMATORY SURVEY REPORT FOR THE CONFIRMATORY SURVEY OF THE DEFENSE LOGISTICS AGENCY DEFENSE NATIONAL STOCKPILE CENTER NEW HAVEN DEPOT NEW HAVEN, INDIANA
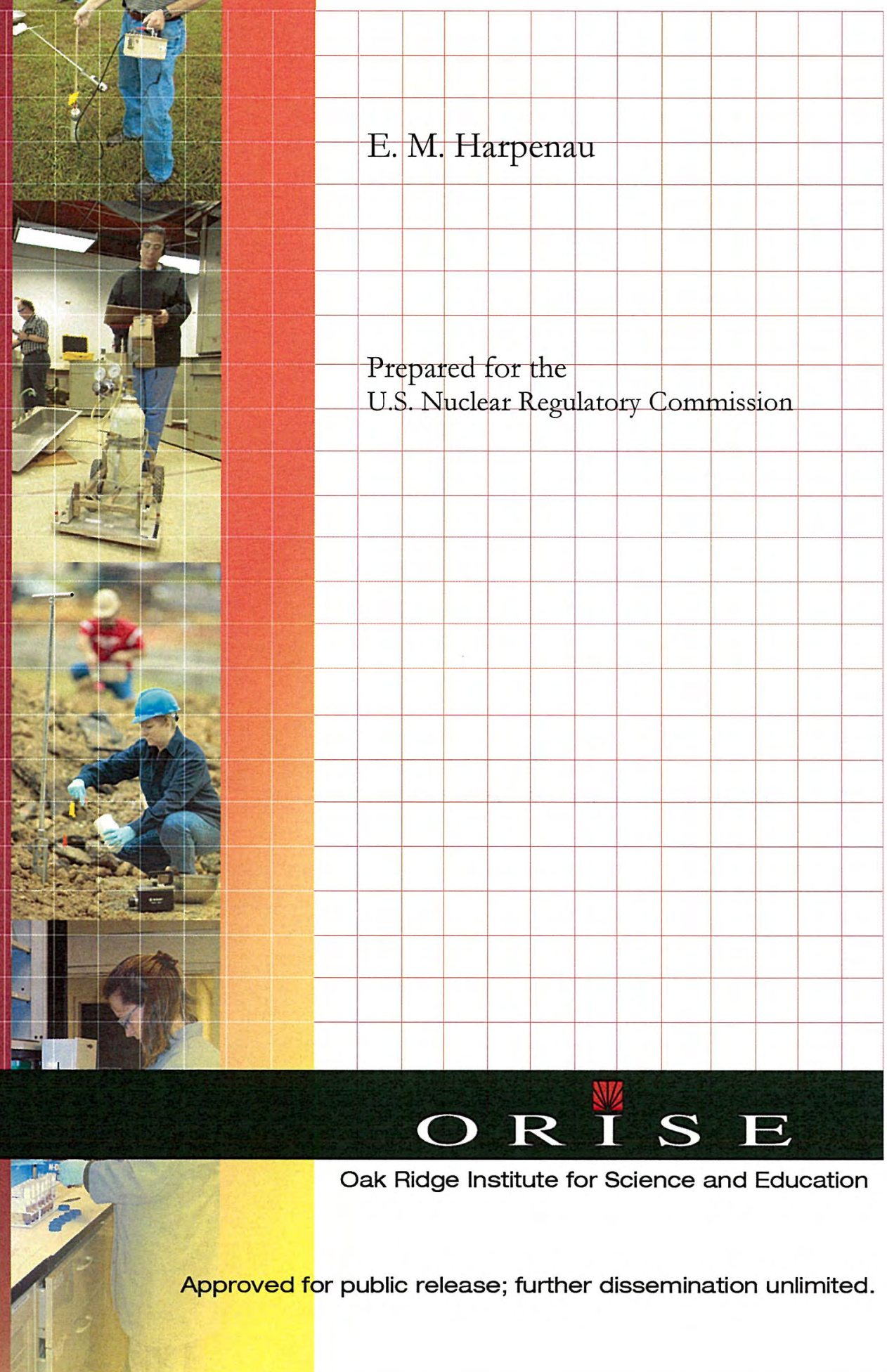

Oak Ridge Institute for Science and Education

Approved for public release; further dissemination unlimited. 
The Oak Ridge Institute for Science and Education (ORISE) is a U.S. Department of Energy facility focusing on scientific initiatives to research health risks from occupational hazards, assess environmental cleanup, respond to radiation medical emergencies, support national security and emergency preparedness, and educate the next generation of scientists. ORISE is managed by Oak Ridge Associated Universities. Established in 1946, ORAU is a consortium of 97 colleges and universities.

\section{NOTICES}

The opinions expressed herein do not necessarily reflect the opinions of the sponsoring institutions of Oalk Ridge Associated Universities.

This report was prepared as an account of work sponsored by the United States Government. Neither the United States Government nor the U.S. Department of Energy, nor any of their employees, makes any warranty, expressed or implied, or assumes any legal liability or responsibility for the accuracy, completeness, or usefulness of any information, apparatus, product, or process disclosed, or represents that its use would not infringe on privately owned rights. Reference herein to any specific commercial product, process, or service by trade name, mark, manufacturer, or otherwise, does not necessarily constitute or imply its endorsement or recommendation, or favor by the U.S. Government or any agency thereof. The views and opinions of authors expressed herein do not necessarily state or reflect those of the U.S. Government or any agency thereof. 


\title{
CONFIRMATORY SURVEY OF THE \\ DEFENSE LOGISTICS AGENCY \\ DEFENSE NATIONAL STOCKPILE CENTER \\ NEW HAVEN DEPOT \\ NEW HAVEN, INDIANA
}

\author{
Prepared by \\ E. M. Harpenau \\ and \\ W. C. Adams

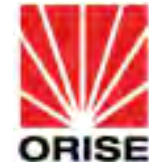 \\ Independent Environmental Assessment and Verification Program \\ Oak Ridge Institute for Science and Education \\ Oak Ridge, Tennessee 37831-0017 \\ Prepared for the \\ U.S. Nuclear Regulatory Commission
}

FINAL REPORT

FEBRUARY 2010

Prepared by the Oak Ridge Institute for Science and Education, under interagency agreement (NRC FIN No. F1008) between the U.S. Nuclear Regulatory Commission and the U.S. Department of Energy. 


\section{CONFIRMATORY SURVEY OF THE \\ DEFENSE LOGISTICS AGENCY \\ DEFENSE NATIONAL STOCKPILE CENTER \\ NEW HAVEN DEPOT \\ NEW HAVEN, INDIANA}

Prepared by:

E. M. Harpenau, Asst. Project Leader

Date: $2 / 18 / 10$

Independent Environmental Assessment and Verification

Prepared by: Loreac. Asarr

W. C. Adams, Project Leader

Independent Environmental Assessment and Verification

Date: $2 / 18 / 2010$

Reviewed by:

Griva y. Bavley for

T. J. Vitkus, Survey Projects Manager

Independent Environmental Assessment and Verification

Reviewed by:

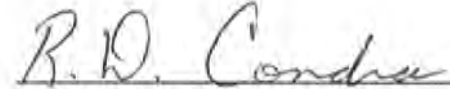

Date: $2 / 19 / 10$

R. D. Condra, Laboratory Manager

Independent Environmental Assessment and Verification

Reviewed by:

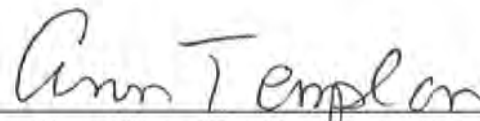

F. A. Templon, Quality Manager

Date: $2 / 19 / 10$

Independent Environmental Assessment and Verification

Date: $2 / 19 / 10$ 


\section{ACKNOWLEDGMENTS}

The authors would like to acknowledge the significant contributions of the following staff members:

\section{FIELD AND SUPPORT STAFF}

W. C. Adams

E. M. Harpenau

A. C. Kirthlink

J. A. Viars

\section{LABORATORY STAFF}

R. D. Condra

J. S. Cox

W. P. Ivey

W. F. Smith

\section{CLERICAL STAFF}

J. L. Clary

R. M. Fink

K. M. Moore

A. Ramsey

\section{ILLUSTRATORS}

A. M. Hood

J. A. Viars 


\section{TABLE OF CONTENTS}

PAGE

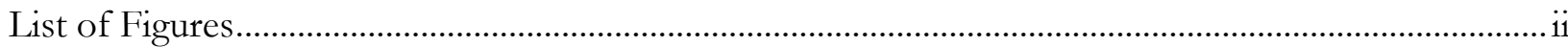

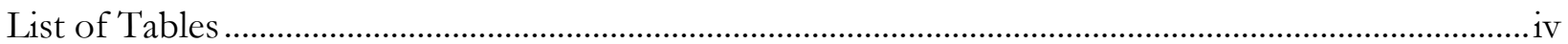

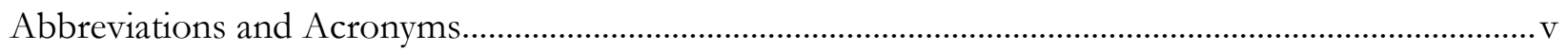

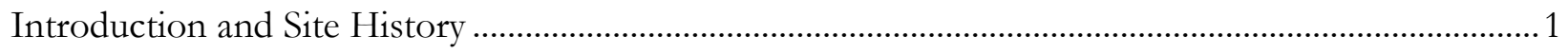

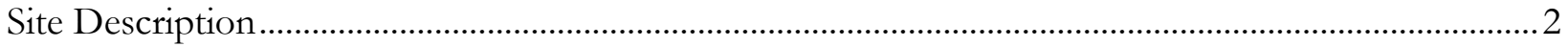

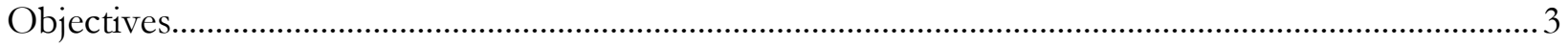

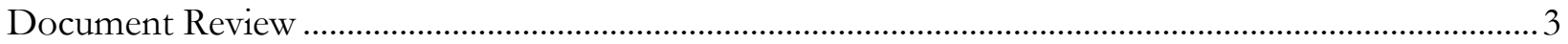

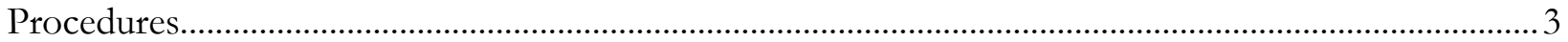

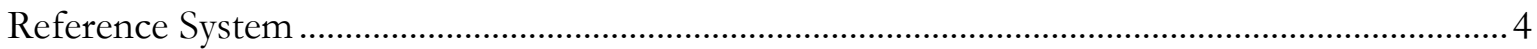

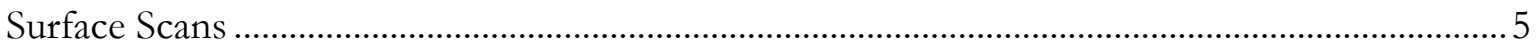

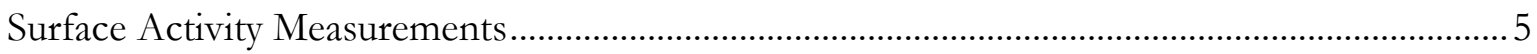

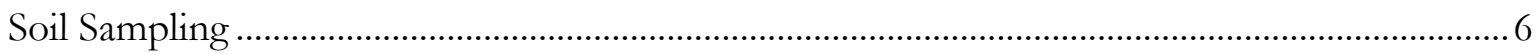

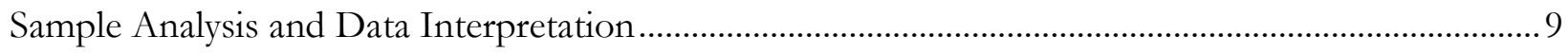

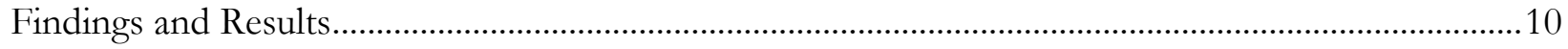

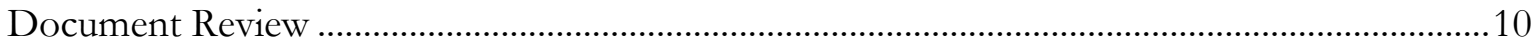

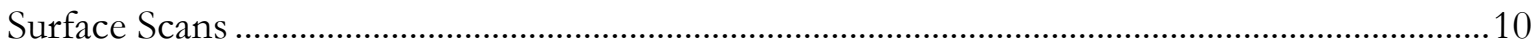

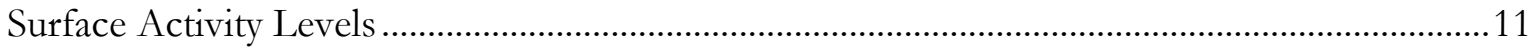

Radionuclide Concentrations in Soil Samples ............................................................................11

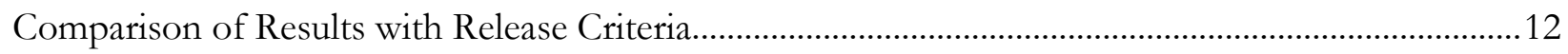

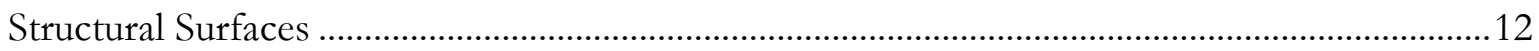

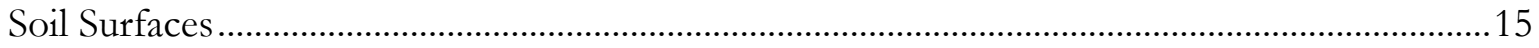

Summary

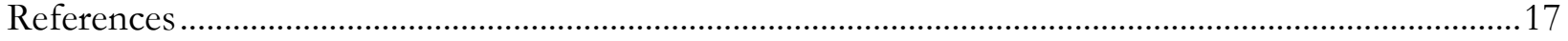

Appendices:
Appendix A: Figures
Appendix B: Tables
Appendix C: Major Instrumentation
Appendix D: Survey and Analytical Procedures 


\section{LIST OF FIGURES}

$\underline{\text { PAGE }}$

Figure 1: Example Land Area Unit With Ranked Set Sampling Locations..............................................

Figure A-1: Location Of The DNSC New Haven Depot ................................................................... A-1

Figure A-2: DNSC New Haven Depot—Buildings, Stockpiles and Areas......................................... A-2

Figure A-3: DNSC New Haven Depot-Outdoor Survey Areas and

Survey Unit Classifications....................................................................................... A-3

Figure A-4: Survey Units 1-6-Survey Area and Gamma Scans ..................................................... A-4

Figure A-5: Group 1 (Survey Units 3, 4 and 9) Confirmation Population, Survey Areas-Ranked

Set Sampling Measurement Locations.............................................................................. A-5

Figure A-6: Group 2 (Survey Units 1, 2, 5 and 6) Confirmation Population, Survey

Areas-Ranked Set Sampling Measurement Locations........................................................ A-6

Figure A-7: Group 3 (Survey Unit 210, Section 2, Area 6) Confirmation Population, Survey

Areas-Ranked Set Sampling Measurement Locations.

Figure A-8: Group 1 (Survey Units 3 and 4) Confirmation Population, Survey Areas-Soil

Sampling Locations.....

Figure A-9: Group 1 (Survey Unit 9) Confirmation Population, Survey Areas-Judgmental

Soil Sampling Locations

Figure A-10: Group 2 (Survey Units 1, 2, 5 and 6) Confirmation Population, Survey

Areas-Soil Sampling Locations.

Figure A-11: Group 3 (Survey Unit 210, Section 2, Area 6) Confirmation Population, Survey

Areas_-Soil Sampling Locations.....

Figure A-12: Survey Unit 145—Survey Area and Gamma Scans.................................................... A-12

Figure A-13: Survey Unit 145-Direct Measurement Locations ........................................................ A-13

Figure A-14: Survey Units 8 And 9- Survey Area and Gamma Scans ........................................... A-14

Figure A-15: Survey Unit 8-Direct Measurement Locations............................................................ A-15

Figure A-16: Survey Unit 219a—Direct Measurement Locations..................................................... A-16

Figure A-17: Building 210 Section 2-Survey Area and Alpha Plus Beta Scans ............................A-17

Figure A-18: Building 210 Section 3-Survey Area and Alpha Plus Beta Scans ........................... A-18

Figure A-19: Building 215 Section 4-Survey Area and Alpha Plus Beta Scans ............................. A-19

Figure A-20: Building 210 Section 2 Class 1 Survey Units-Direct Measurement Locations ......... A-20

Figure A-21: Building 210 Section 2 Floor and Walls_-Direct Measurement Locations................ A-21

Figure A-22: Building 210 Section 3 Floor-Direct Measurement Locations .................................. A-22

Figure A-23: Building 215 Section 4-Direct Measurement Locations ............................................ A-23 


\section{LIST OF FIGURES (cont.)}

$\underline{\text { PAGE }}$

Figure A-24: Verification Outdoor Gamma Scan Count Rate

Histogram (Combined Data) ....................................................................................... A-24

Figure A-25: Verification Indoor Alpha Plus Beta Scan Count Rate

Histogram (Combined Data) 


\section{LIST OF TABLES}

PAGE

Table 1: New Haven Depot Survey Unit Summary .........................................................................

Table 2: Summary Results for Alpha Activity Measurements .................................................................11

Table 3: Radionuclide Concentrations In Soil Samples Summary Results...........................................12

Table 4: Radionuclide Concentrations In Judgmental Soil Samples Summary Results........................12

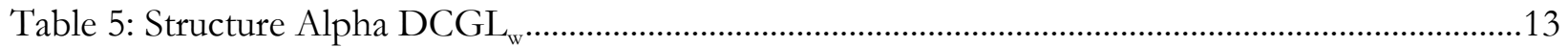

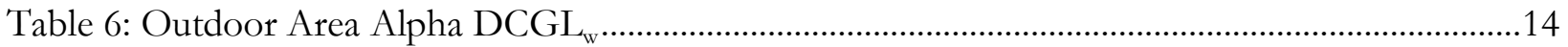

Table B-1: Ranked Set Sampling Gamma Measurements.................................................................

Table B-2: Ranked Set Sampling Soil Sample Concentrations ................................................................

Table B-3: Structural Surface Activity Measurements ............................................................................

Table D-1: MDC Derived From Total Absorption Peak .................................................................... D-4 


\section{ABBREVIATIONS AND ACRONYMS}

\begin{tabular}{|c|c|}
\hline $\mathrm{cm}$ & centimeter \\
\hline cpm & counts per minute \\
\hline DCGL & derived concentration guideline level \\
\hline DNSC & Defense National Stockpile Center \\
\hline DOE & U.S. Department of Energy \\
\hline $\mathrm{dpm} / 100 \mathrm{~cm}^{2}$ & $\begin{array}{l}\text { disintegrations per minute per one-hundred square } \\
\text { centimeters }\end{array}$ \\
\hline EPA & U.S. Environmental Protection Agency \\
\hline FSS & final status survey \\
\hline FSSR & final status survey report \\
\hline GPS & global positioning system \\
\hline GSA & General Service Administration \\
\hline ITP & Intercomparison Testing Program \\
\hline $\mathrm{kg}$ & kilogram \\
\hline MAPEP & Mixed Analyte Performance Evaluation Program \\
\hline MARSSIM & Multi-Agency Radiation Survey and Site Investigation Manual \\
\hline MDC & minimum detectable concentration \\
\hline $\mathrm{MeV}$ & million electron volts \\
\hline $\mathrm{m}^{2}$ & square meter \\
\hline NAD & North American Datum \\
\hline $\mathrm{NaI}$ & sodium iodide \\
\hline NHD & New Haven Depot \\
\hline NRC & U.S. Nuclear Regulatory Commission \\
\hline NRIP & NIST Radiochemistry Intercomparison Program \\
\hline ORAU & Oak Ridge Associated Universities \\
\hline ORISE & Oak Ridge Institute for Science and Education \\
\hline $\mathrm{pCi} / \mathrm{g}$ & picocuries per gram \\
\hline RAM & radioactive material \\
\hline RSS & ranked set sampling \\
\hline SOR & sum-of-ratios \\
\hline TAP & total absorption peak \\
\hline Th-232 & Thorium-232 \\
\hline $\mathrm{U}-238$ & Uranium-238 \\
\hline VSP & Visual Sample Plan \\
\hline
\end{tabular}




\section{CONFIRMATORY SURVEY OF THE \\ DEFENSE LOGISTICS AGENCY \\ DEFENSE NATIONAL STOCKPILE CENTER \\ NEW HAVEN DEPOT \\ NEW HAVEN, INDIANA}

\section{INTRODUCTION AND SITE HISTORY}

In 1946, a National Stockpile program began with the goal of mitigating dependence on foreign sources of vital materials during times of national emergencies. The New Haven Depot (NHD) in New Haven, Indiana, formerly the Casad Depot, was used to store 29 different types of strategic materials. The NHD is owned by the General Services Administration (GSA) and was operated by the Defense National Stockpile Center (DNSC).

Historically, the primary mission at the NHD was to store metallurgical ores and materials necessary for manufacturing defense and/or strategic materials. The DNSC stored columbium/tantalum ores and concentrates, tungsten ores and concentrates, zirconium ore, rare earth sodium sulfate, monazite, tungsten metal scrap, and bastnasite throughout the various warehouses and outdoor areas of the NHD. These materials contained sufficient amounts of natural uranium and thorium to require licensing under U.S. Nuclear Regulatory Commission (NRC) regulations and were stored by the DNSC in accordance with NRC License STC-133.

Materials like zirconium ore were stored in outdoor piles while other materials containing licensable quantities of uranium and thorium packaged in wooden boxes and drums were stored in designated bays within the warehouses located on the site. Specifically, the outdoor storage area for the licensed zirconium material was designated as Pile 111 and was located in the NHD open area designated as 7A. A portion of the zirconium in Pile 111 originated from DNSC depots in Jeffersonville, Indiana and Columbus, Ohio. Pile 111A contained contaminated soils that were removed from the base of the former Jeffersonville and Columbus Depots zirconium piles.

In 2000, all zirconium ore was sold and loaded into railcars at the Area 7A storage location for shipment to the new owner. The loaded railcars were then moved to the rail scale where the railcar loads were adjusted to maximum acceptable weight for transport. After the railcars reached maximum weight, they were moved to a shrink-wrapping area and shrink-wrapped to prevent loss of 
the material during transport. Some of the material was spilled during the loading operations which resulted in localized contamination of the associated land area. The largest accumulations of zirconium residues were identified on the paved road from Area 7A to the rail scale and the railroad tracks at the southern end of the Depot in front of Building 111. Other handling processes on the western side of the Depot resulted in the spillage of smaller, more discrete ore residues. The containerized licensed materials at NHD were stored in Warehouses 210 through 215 and several other smaller buildings.

The DNSC is in the process of closing a number of depots across the country and requesting license amendments to remove those applicable depots from License STC-133. DNSC contracted with Cabrera Services, Inc. (Cabrera) to remediate remaining impacted areas of the NHD and to perform final status surveys (FSS). Prior to performing the FSS, all licensed radioactive material (RAM) and residual licensed RAM on roadways and the adjacent ground surfaces were removed and the interior structural surfaces were remediated. The radionuclides of concern were natural thorium and uranium and the associated daughter products of the two decay series.

\section{SITE DESCRIPTION}

The New Haven Depot consists of 268 acres of land three miles east of Fort Wayne, Indiana off of State Route 14 (Figure A-1). There is a six foot high fence topped with barbed wire that surrounds the site. The site has a security officer controlling access, but is otherwise unoccupied. There are a number of large storage warehouses and other support buildings. The large warehouses used for RAM storage- Warehouses 210 through 215—are approximately 55 meters wide, 293 meters long and are framed with wood, concrete, or concrete-block that support wooden roof decks (Figure A-2). Each warehouse is divided equally into four approximately 55-meter by 72-meter sections. Each section is then further subdivided into 79 equally sized storage bays. Other radiologically impacted buildings where RAM was handled and/or stored included buildings 136, 141, 145 (only the footprint remains) and 146 (Figure A-2). For the former exterior RAM storage piles, Pile 111 has a footprint surface area of 1,650 square meters $\left(\mathrm{m}^{2}\right)$ and Pile 111A has a footprint surface area of $650 \mathrm{~m}^{2}$. The footprints of these piles are outlined by Survey Units 1 through 6 as indicated in Figure A-3. 


\section{OBJECTIVES}

The objectives of the radiological confirmatory survey were to collect adequate radiological data for use in evaluating the radiological condition of NHD land areas, warehouses, and support buildings. The data generated from the confirmatory survey activities were used to evaluate the results of the Final Status Survey Report (FSSR) submitted by Cabrera Services (Cabrera 2009). Cabrera has stated that all radioactive materials have been removed and that remediation of the open land areas and structure surfaces was complete, and that the NHD meets the criteria for unrestricted use.

\section{DOCUMENT REVIEW}

Oak Ridge Institute for Science and Education (ORISE) reviewed the FSS procedures for the NHD and the FSS report. Information was evaluated to assure that FSS procedures were appropriate for the radionuclides of concern and that residual activity levels satisfied the established radiological release criteria.

\section{PROCEDURES}

ORISE personnel visited the NHD from October 5 through 8, 2009 to perform visual inspections and independent measurements and sampling. The confirmatory survey activities were conducted in accordance with a site-specific confirmatory survey plan and the ORISE Survey Procedures and Oak Ridge Associated Universities (ORAU) Quality Program Manuals (ORISE 2009a and 2008 and ORAU 2009).

The collective site areas surveyed consisted of nine structural survey units and nine land area survey units totaling approximately $35,000 \mathrm{~m}^{2}$. Each survey unit was classified in accordance with the Multi-Agency Radiation Survey and Site Investigation Manual (MARSSIM), based on contamination potential (NRC 2000). A description of each classification is as follows:

Class 1: Areas that have a significant potential for radioactive contamination (based on site operating history) or known contamination (based on previous radiological surveys) that exceeds the expected derived concentration guideline level $\left(\mathrm{DCGL}_{\mathrm{W}}\right)$. 
Class 2: $\quad$ Areas that have, or had prior to remediation, a potential for radioactive contamination or known contamination, but are not expected to exceed the DCGL $\mathrm{W}_{\mathrm{W}}$.

Class 3: Any impacted areas that are not expected to contain residual contamination, or are expected to contain levels of residual contamination at a small fraction of the DCGL $_{\mathrm{w}}$.

Survey unit information is summarized in the Table 1 and in Figures A-2 and A-3.

\begin{tabular}{|c|c|c|}
\hline \multicolumn{3}{|c|}{$\begin{array}{c}\text { TABLE 1: } \\
\text { NEW HAVEN DEPOT SURVEY UNIT SUMMARY }\end{array}$} \\
\hline Survey Unit ID & Type & Classification \\
\hline 145-F & Concrete Pad & 3 \\
\hline $210-2-1$ & Building & 1 \\
\hline $210-2-2$ & Building & 1 \\
\hline $210-2-3$ & Building & 1 \\
\hline $210-2-4$ & Building & 1 \\
\hline $210-2-\mathrm{F}$ & Building & 3 \\
\hline $210-3-\mathrm{F}$ & Building & 3 \\
\hline $210-2-\mathrm{F}$ & Building & 3 \\
\hline $210-2-\mathrm{W}$ & Building & 3 \\
\hline $215-4-\mathrm{F}$ & Building & 3 \\
\hline 219A-F & Building & 2 \\
\hline 1 & Land Area & 1 \\
\hline 2 & Land Area & 1 \\
\hline 3 & Land Area & 1 \\
\hline 4 & Land Area & 2 \\
\hline 5 & Land Area & 1 \\
\hline 6 & Land Area & 1 \\
\hline 8 & Rail Scale Concrete Pad & 2 \\
\hline 9 & Land Area & 1 \\
\hline $210-2-6$ & Land Area & 1 \\
\hline
\end{tabular}

\section{REFERENCE SYSTEM}

Exterior survey results were referenced to prominent site features and/or global positioning system (GPS) coordinates. The coordinate reference system used for the confirmatory survey was: North American Datum (NAD) 1983 State Plane Indiana East FIPS 1301 Feet. Building survey 
information was referenced to the building number, storage bay designation and/or specific X, Y coordinates from the southwest corner of the respective survey unit floor and lower left corner of walls. A written record of survey information was maintained on site drawings.

\section{SURFACE SCANS}

High and medium density gamma radiation surface scans were conducted over all land area survey units (Figures A-4 and A-14). Surface scans were performed using Sodium iodide (NaI) scintillation detectors coupled to ratemeter-scalers with audible indicators. Detectors for exterior surveys were also coupled to GPS systems that enabled real-time gamma count rate and position data capture. Field personnel relied on the audio output to identify and mark for further investigations any locations of elevated direct gamma radiation that might suggest the presence of residual contamination.

Structural surfaces, such as floors, lower walls, and concrete pads were scanned for alpha plus beta and gamma radiation (Figures A-12, A-14 and A-17 through A-19). Scan density was dependent on survey unit classification. Class 1 survey units received high density scans, Class 2 medium density and Class 3 low density. NaI scintillation detectors were used for direct gamma radiation scans and gas proportional detectors for direct alpha plus beta radiation scanning. Detectors were coupled to ratemeters or ratemeter-scalers with audible indicators. Locations of elevated direct radiation were marked for further investigation. Identification of areas requiring additional investigation was based on instrument count rate action levels established at the site.

\section{SuRfaCe ACTIVITy MEASUREMENTS}

Construction material specific backgrounds were determined in areas without a history of radioactive material use but of similar material and construction. These reference areas included Buildings $141 \mathrm{C}$ and 211 Section 1. The selection of these areas was based on program personnel experience and professional judgment in order to have the best possible reference material specific backgrounds. Ambient background measurements were derived from instrument setups. 
Direct measurements to quantify total alpha and alpha plus beta activity levels were performed at random locations within each survey unit selected for the confirmatory survey. The number of random measurements was calculated using the FSS data as inputs. Visual Sample Plan (VSP) version 5.4.1 was used to plot six locations for each of the survey units on building surfaces while incorporating a quasi-random approach that minimized spatial clustering of measurement locations. Judgmental direct measurements were made at any locations of elevated direct radiation detected by surface scans. Direct measurements were made using gas proportional detectors coupled to ratemeter-scalers. Direct measurement locations for building survey units are indicated on Figures A-13, A-15, A-16 and A-20 through A-23.

\section{SOIL SAMPLING}

A ranked set sampling (RSS) approach was used to design the confirmatory soil sampling plan (EPA 2002). RSS provided a methodology to estimate the mean concentration of a population without requiring the assumption of a normal distribution. The process combines random sampling with the use of professional judgment to select sampling locations. The professional judgment relied upon the ability to assess the relative magnitude of gamma radiation levels between randomly selected locations. In this case, the gamma count rate data collected at randomly selected locations provided the measurable field screening method that correlates with the relative concentrations of the gamma emitting contaminants of concern. The count rate data obtained were then used to select a specific sampling location.

The following example explains the process:

- The Visual Sampling Plan v.5.4.1 RSS module was used to determine the necessary number of soil samples to estimate the mean. The number of measurements was based on the expected standard deviation and desired confidence level of the estimated mean.

- For this example, assume that the systematic planning process resulted in $n=12$ soil samples to estimate the mean.

- The next step was to use a replication process on a larger random population from which the locations for the 12 soil samples will be selected.

- The replication process was referred to as a cycle, designated as $r$. 
- $\quad$ Each cycle $(r)$ consists of multiple sets; sets were designated as $m$.

- Each set $(m)$ is comprised of a set size, or field assessment locations. The data from each set were ultimately the values that were ranked, for this example the ranked values were direct gamma counts. The set size should consist of two to five field assessment locations. For this project, a set size consisted of three locations. The gamma count data collected from the three locations associated with each set were ranked as being either low, medium, or high gamma count locations. The three ranking categories established the set size.

- The total number of repetitive cycles $(r)$ is a function of $n(12)$ and $m$ (3) - or simply defined as $n=m \times r . \quad r$ for this example would therefore be $4(r=12 / 3)$.

- The number of field assessment locations per cycle, was a function of the set size and is simply $m^{2}$. The total number of field assessment locations was then defined as $m^{2} \times r$ or in this example $3^{2} \times 4=36$.

- The 36 locations were then both randomly grouped into cycle/sets and distributed in the survey area. The nomenclature for identifying a specific assessment location was cycle \#-set\#-arbitrary sequence \# (1, 2, or 3). The first location in cycle 1 of set 1 was designated as 1-1-1. Mapping is color coded (based on cycle ID) using geometric shapes (based on set ID) to visually show the population of assessment locations.

- Specific measurement locations were generated via either a pseudo- or quasi-random approach. 


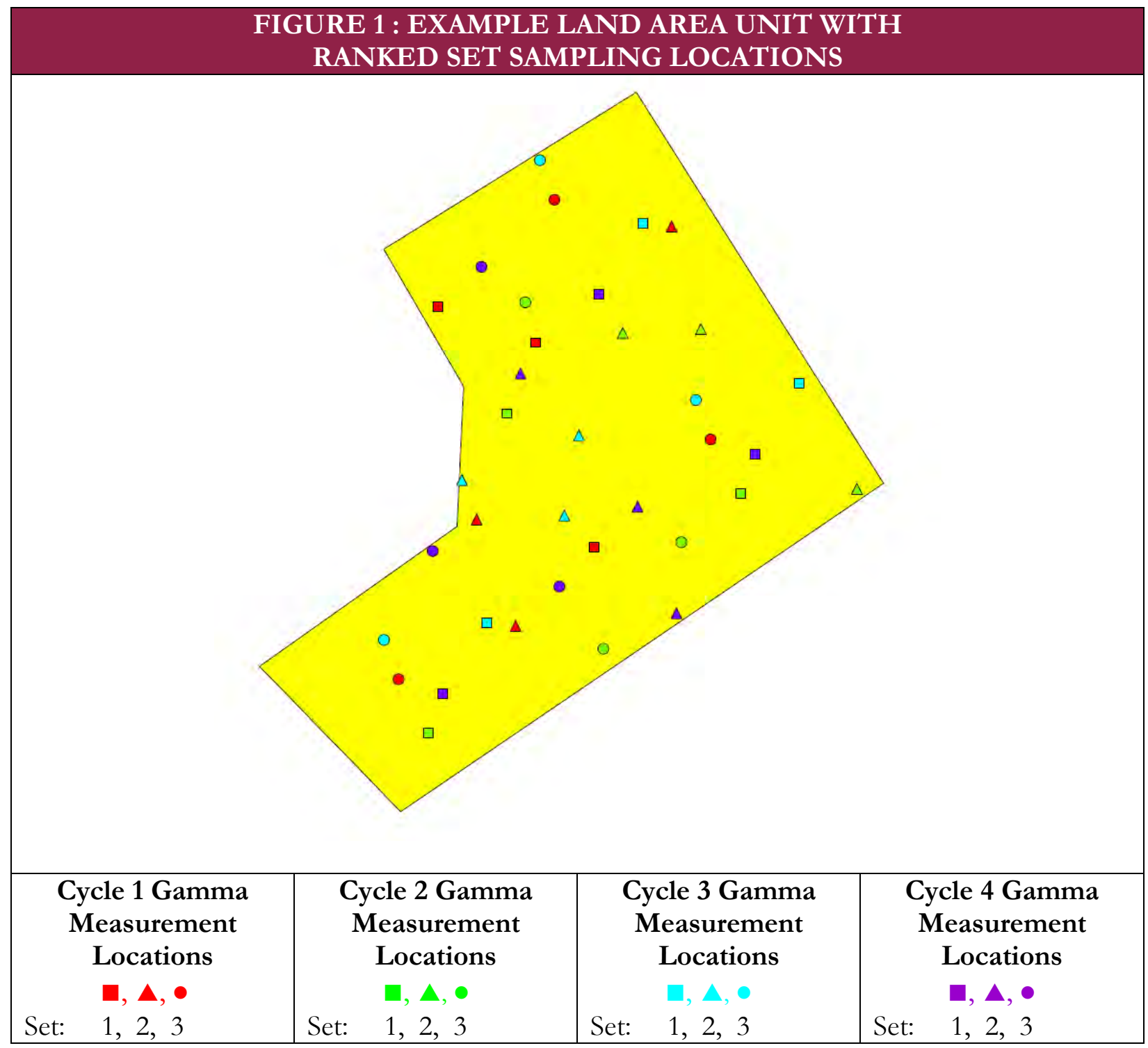

Figure 1 is an example of an RSS measurement/sampling plan.

One-minute gamma measurements were collected at each of the 36 assessment locations and the data within a given cycle-set were then ranked as exhibiting either the lowest, medium, or highest gamma count. Soil samples were collected in accordance with the following process within each of the four cycles: Set 1, lowest gamma radiation location; Set 2 medium location; Set 3 highest location. Table B-1 provides the RSS method showing field assessment data and the location selected for soil sampling. 
Cabrera Services, Inc. survey unit FSS data were used to determine the number of random confirmatory samples necessary to verify the mean concentrations. Specifically, the inputs used were the respective DCGLs for the primary natural radionuclides Thorium-232 (Th-232) + C and Uranium-238 (U-238) + C. There were three area sample planning groups as follows: Survey Units 3, 4 and 9 served as sampling Group 1, Survey Units 1, 2, 5 and 6 were included together as Group 2 and Group 3 was represented by Survey Unit 210-2-6 (a remediated soil area within Building 210 Section 2). The decision to pool the verification data for the survey units was based on the evaluation of the Cabrera Services, Inc.-determined mean concentration and standard deviation of the contaminants of concern for each survey unit. Figures A-5 through A-7 illustrate the RSS gamma measurement locations

Twelve random surface (0 to $15 \mathrm{~cm}$ ) soil samples were collected from each group. The specific random coordinate sampled was from the preliminary random coordinate pool of 36 locations for each group. Figures A-8, A-10 and A-11 illustrate the random ranking locations and the soil sample locations.

\section{SAMPLE ANALYSIS AND DATA INTERPRETATION}

Samples and data were returned to the ORISE laboratory in Oak Ridge, Tennessee for analysis and interpretation. Sample analyses were performed in accordance with the ORISE Laboratory Procedures Manual (ORISE 2009b). Direct measurement results were reported in units of disintegrations per minute per one-hundred square centimeters $\left(\mathrm{dpm} / 100 \mathrm{~cm}^{2}\right)$. Soil samples were analyzed by gamma spectroscopy for Th-232 + C and U-238 + C. The spectra were also reviewed for other identifiable photopeaks. Soil sample results were reported in units of picocuries per gram (pCi/g).

The data generated were compared with the approved release criteria established for the NHD. The Defense Logistics Agency requested site-specific release criteria that allowed soil concentrations to contain up to $2.5 \mathrm{pCi} / \mathrm{g}$ of Th-232 and $2.3 \mathrm{pCi} / \mathrm{g}$ of U-238. These NRC-approved criteria also applied to any of the radionuclides in the Th-232 or U-238 decay series individually. Additional information regarding instrumentation and procedures may be found in Appendices C and D. 


\section{FINDINGS AND RESULTS}

\section{DOCUMENT REVIEW}

ORISE's review of Cabrera's project documentation indicated that most procedures and methods implemented for the FSS were appropriate and that the resultant data were acceptable. However, when incorporating the MARSSIM based approach for the design of FSS, the 2 pi efficiency of survey instruments combined with a surface efficiency factor is typically the norm used for direct measurements. Cabrera's project documentation used 4 pi efficiencies for their FSS activities. A 4 pi efficiency would result in biasing residual surface activities lower than the 2 pi efficiencies when combined with the surface efficiency factor. The low bias is a result of not accounting for surface attenuation factors. This issue of Cabrera collected data using inappropriate efficiencies was mentioned in the confirmatory survey plan and within correspondence with the NRC site representative on September 30, 2009.

Further review of the FSSR revealed that the survey unit identified as Building 129A was represented incorrectly. The ORISE survey team with the assistance of site personnel determined that Building 129A did not exist at the NHD, and its designation in the FSSR actually referred to Building 219A at the Rail Scale. This correction was made on-site and the appropriate building number was assigned for this report.

\section{SURFACE SCANS}

\section{$\underline{\text { Soil Surfaces }}$}

Gamma radiation surface scans identified two locations of elevated activity in Survey Unit 9. The GPS coordinates were recorded and a judgmental soil sample was collected from each location (Figure A-9). Land area scans ranged from 1,200 to 5,651 counts per minute (cpm) with the variability in the ambient gamma radiation levels consistent with the localized area topography and geology. Gamma scan results are illustrated in Figures A-4, A-12 (SU145 pad) and A-14 for each area. Figure A-24 provides a frequency histogram of the combined soil/exterior area gamma scan count rate population. 


\section{Structural Surfaces}

On interior structural surfaces, alpha + beta scan count rates generally ranged from 951 to 2,300 cpm with the 43-37 large area gas proportional detector, and 200 to $400 \mathrm{cpm}$ using the smaller hand-held gas proportional detector. Data are provided as the gross, observed count rates for alpha + beta scans in Figures A-17 through A-19. Figure A-25 provides a frequency histogram of the combined alpha + beta count rate data population.

\section{SURFACE ACTIVITY LEVELS}

Individual total alpha and alpha + beta surface activity measurements are documented in Table B-3. NHD structural surface activity DCGL $\mathrm{W}_{\mathbb{W}}$ is for alpha activity only; alpha + beta scan range and surface activity measurements were collected to supplement the alpha activity data. The summary data for the confirmatory alpha activity measurements are presented in Table 2.

\begin{tabular}{||c|c||}
\hline \multicolumn{2}{|c|}{ TABLE 2: } \\
\hline \multicolumn{2}{|c|}{$\begin{array}{c}\text { SUMMARY RESULTS FOR ALPHA } \\
\text { ACTIVITY MEASUREMENTS }\end{array}$} \\
\hline Survey Unit & $\begin{array}{c}\text { Alpha Activity Range } \\
\text { (dpm/100 } \mathbf{~ c m}^{2} \text { ) }\end{array}$ \\
\hline \hline SU145-F & 15 to 134 \\
\hline SU210-2-1 & -1 to 39 \\
\hline SU210-2-2 & -33 to 31 \\
\hline SU210-2-3 & -1 to 174 \\
\hline SU210-2-4 & -25 to 38 \\
\hline SU210-2-F & -1 to 39 \\
\hline SU210-3-F & -17 to 31 \\
\hline SU210-W & -10 to 34 \\
\hline SU215-4-F & -17 to 15 \\
\hline SU219A & -13 to 2 \\
\hline SU8 Rail Scale & 7 to 174 \\
\hline
\end{tabular}

\section{RADIONUCLIDE CONCENTRATIONS IN SOIL SAMPLES}

The data for the ORISE radionuclide concentrations in individual samples and the sum-of-ratios (SOR) are provided in Table B-2. The summary data for the three combined survey groupings are presented in Table 3 as gross soil radionuclide concentration. When calculating the SOR values 
presented in Table B-2, ORISE determined the Net Concentration values for the confirmatory soil samples by subtracting the average background concentrations as determined by Cabrera in the FSSR.

\begin{tabular}{|c|c|c||}
\hline \multicolumn{3}{|c|}{ TABLE 3: } \\
RADIONUCLIDE CONCENTRATIONS IN SOIL SAMPLES \\
SUMMARY RESULTS \\
\hline Survey Area Groupings & Th-232 + C (pCi/g) & U-238 + C (pCi/g) \\
\hline \hline Group 1: Survey Units 3, 4, 9 & 0.16 to 1.04 & 0.74 to 2.75 \\
\hline Mean Concentration & 0.83 & 1.74 \\
\hline Group 2: Survey Units 1, 2, 5, 6 & 0.29 to 1.52 & 0.86 to 3.06 \\
\hline Mean Concentration & 0.67 & 1.69 \\
\hline Group 3: Survey Units 210-2-6 & 0.55 to 0.75 & 1.48 to 2.02 \\
\hline Mean Concentration & 0.64 & 1.66 \\
\hline
\end{tabular}

${ }^{\mathrm{a}}$ Gross soil concentration.

The radionuclide concentrations for the two judgmental soil samples collected from Survey Unit 9 are provided in Table 4. A review of the FSSR indicated that the ORISE judgmental soil sample locations coincide with Cabrera biased soil samples as indicated in Figure 6-6 of the FSSR (Cabrera 2009). It should also be noted that the two judgmental sample locations comprise two different contaminants based on the differences in the Th-232 and U-238 ratios.

\begin{tabular}{|c|c|c|}
\hline \multicolumn{3}{|c|}{ TABLE 4: } \\
\multicolumn{3}{|c|}{ RADIONUCLIDE CONCENTRATIONS IN JUDGMENTAL SOIL SAMPLES } \\
SUMMARY RESULTS
\end{tabular}

${ }^{\mathrm{a}}$ Gross soil concentration.

\section{COMPARISON OF RESULTS WITH RELEASE CRITERIA}

\section{STRUCTURAL SURFACES}

Confirmatory survey data for structural surfaces were compared with the structural site-specific gross DCGL for the evaluated SUs. The final resultant surface DCGLs in Tables 5 and 6 were 
based on surface activity screening values from NUREG/CR-5512 that were further modified based on the total number of alphas emitted in each of the applicable decay chains and the percent contribution from each chain. Then applicable RAM fractions were applied for mixtures of materials stored in different areas of the site.

\begin{tabular}{|c|c|c|}
\hline \multicolumn{3}{|c|}{$\begin{array}{c}\text { TABLE 5: } \\
\text { STRUCTURE ALPHA DCGL } \text { DW }_{\mathbb{W}}\end{array}$} \\
\hline Building & Impacted Structure Area & $\begin{array}{l}\text { Alpha DCGL } \\
\left(\mathrm{dpm} / 100 \mathrm{~cm}^{2}\right)\end{array}$ \\
\hline 124 & All locations & 100 \\
\hline 136 & All locations & 38 \\
\hline 141 & All locations & 100 \\
\hline 145 (footprint) & All locations & 100 \\
\hline 146 & All locations & 100 \\
\hline \multirow[b]{2}{*}{210} & Sections 1, 2 and 3: All locations & 38 \\
\hline & $\begin{array}{l}\text { Section 4: Bays } 2-5,8,9,12-14,32-33,35,43,45,46,48, \\
52-54,56,58 \text { and } 76 \text { only }\end{array}$ & 100 \\
\hline 211 & Section 1 and 2: All locations & 55 \\
\hline \multirow{2}{*}{212} & Section 1: Bays 11, 31, 37, 41, 51, 61 and 71 & 100 \\
\hline & Section 2: Bays 11, 12 and 21 & 100 \\
\hline \multirow{4}{*}{213} & Section 1: All locations & 38 \\
\hline & Section 2: Bays 12, 13, 15 and 16 & 38 \\
\hline & Section 3: Bays 1, 19, 21 and 29 & 100 \\
\hline & $\begin{array}{c}\text { Section 4: Bays 1, 9, 11, 15, 21, 31, 38, 39, 41, 51, 59, 67, } \\
69,75,78 \text { and } 79\end{array}$ & 100 \\
\hline \multirow{2}{*}{214} & Sections 1, 2 and 3: All locations & 38 \\
\hline & Section 4: Bays 41-43, 45 51, 59, 61, 69 and 75-79 & 55 \\
\hline \multirow{3}{*}{215} & $\begin{array}{l}\text { Section 1: Bays 2-4, 11, 12, 13, 22, 23, 25-29, 34-37, 41, 43, } \\
\qquad 44,45,62 \text { and } 73-75\end{array}$ & 38 \\
\hline & Section 2: Bays 36, 41, 42, 46, 52-54, 62 and 63 only & 38 \\
\hline & Section 4: Bays 15, 19, 29, 51-56, 61-65, 68 and 71-79 only & 38 \\
\hline $219 \mathrm{~A}$ & All locations & 100 \\
\hline
\end{tabular}




\begin{tabular}{|c|c|}
\hline \multicolumn{2}{|c|}{$\begin{array}{c}\text { TABLE 6: } \\
\text { OUTDOOR AREA ALPHA DCGL }{ }_{\mathbb{W}}\end{array}$} \\
\hline Impacted Outdoor Areas & Alpha $\operatorname{DCGL}_{\mathrm{W}}\left(\mathrm{dpm} / 100 \mathrm{~cm}^{2}\right)$ \\
\hline Rail Scale & 100 \\
\hline Entry Road and Paved Road to Rail Scale & 100 \\
\hline Railroad Tracks Used for Shrink Wrapping & 100 \\
\hline Railroad Tracks Used for Storage and Transport & 100 \\
\hline
\end{tabular}

Individual direct measurement data are presented within Table B-3. Surface direct measurements for alpha activity within Survey Units 210-2-2, 210-2-W, and 219A were within their applicable $\mathrm{DCGL}_{\mathrm{W}}$ and met the release criteria. However, fifteen percent of the direct structural surface activity measurements exceeded the $\mathrm{DCGL}_{W}$ for the evaluated SUs. The survey units where individual alpha surface activity levels exceeded the survey unit's specific DCGL $_{W}$ are provided in the following paragraphs.

Class 1 survey units identified as having elevated alpha activity in excess of the alpha DCGL $\mathrm{W}_{\mathbb{W}}$ were SUs 210-2-1, 210-2-3, and 210-2-4. Both SUs 210-2-1 and 210-2-4 had one location of $39 \mathrm{dpm} / 100 \mathrm{~cm}^{2}$ that just exceeded the DCGL $\mathrm{w}_{\mathrm{W}}\left(38 \mathrm{dpm} / 100 \mathrm{~cm}^{2}\right)$ and were well within a $1 \mathrm{~m}^{2}$ DCGL $_{\mathrm{EMC}}$. SU 210-2-3 had two locations of elevated alpha activity (79 and $174 \mathrm{dpm} / 100 \mathrm{~cm}^{2}$ ) that exceeded the DCGL $L_{W}$ of $38 \mathrm{dpm} / 100 \mathrm{~cm}^{2}$. These locations were approximately $1 \mathrm{~m}^{2}$ and were less than the calculated alpha activity $\mathrm{DCGL}_{\mathrm{EMC}}$ of $1,360 \mathrm{dpm} / 100 \mathrm{~cm}^{2}$ for an area factor of 36 . In addition to the random alpha direct measurements, the gamma and alpha + beta surface scans of the floor in 210-2-3 identified an area of elevated gamma and alpha + beta activity along a crack in the concrete. Judgmental direct alpha and alpha + beta measurements were taken at that location. The direct measurements indicated an elevated alpha + beta activity of $6,522 \mathrm{dpm} / 100 \mathrm{~cm}^{2}$ within a borehole along the crack in the concrete. The high gamma activity detected during scans and the elevated alpha + beta activity indicate that a contaminant remains within the borehole for Survey Unit 210-2-3.

Class 2 Survey Unit 8 (Rail Scale) had one location of elevated alpha activity $\left(174 \mathrm{dpm} / 100 \mathrm{~cm}^{2}\right)$ that exceeded the DCGL $L_{W}$ of $100 \mathrm{dpm} / 100 \mathrm{~cm}^{2}$. This location was on a crack in the concrete surface on the Rail Scale concrete pad. The confirmatory survey activities indicate that this survey unit was incorrectly classified as a Class 2 survey unit. 
Class 3 survey units identified as having elevated alpha activity in excess of the alpha DCGL $\mathrm{W}_{\mathrm{W}}$ were SUs 210-2- F and 145-F. SU 210-2-F had one location of $39 \mathrm{dpm} / 100 \mathrm{~cm}^{2}$ that just exceeded the DCGL $_{\mathrm{W}}\left(38 \mathrm{dpm} / 100 \mathrm{~cm}^{2}\right)$. SU 145-F, the remaining concrete pad of the former Building 145, had four locations of elevated alpha activity $\left(102,118,126\right.$ and $\left.134 \mathrm{dpm} / 100 \mathrm{~cm}^{2}\right)$ that exceeded the DCGL $_{\mathbb{W}}$ of $100 \mathrm{dpm} / 100 \mathrm{~cm}^{2}$. The confirmatory survey activities indicate that these SUs were incorrectly classified as Class 3 survey units.

\section{SOIL SURFACES}

Radionuclide concentrations in soil samples were directly compared with the Th-232 + C and $\mathrm{U}-238+\mathrm{C}$ release limits of $2.5 \mathrm{pCi} / \mathrm{g}$ and $2.3 \mathrm{pCi} / \mathrm{g}$, respectively. The unity rule was applied in the activity calculations for soil when concentrations of natural thorium and natural uranium were present.

For those ORISE RSS soil samples in Table B-2 in which the gross concentration exceeds the DCGL $_{\mathbb{W}}$, the subtraction of the FSSR site background concentrations $[1.11 \mathrm{pCi} / \mathrm{g}$ of Th-232 and $1.24 \mathrm{pCi} / \mathrm{g}$ of U-238 as provided in the Final Status Survey Report Table 3-11: Reference Area Soil Sample Results (Cabrera 2009)] would put those samples below the DCGL $\mathrm{W}_{\mathrm{W}}$. Therefore, all RSS soil sample results and their associated SORs were less than the established release criteria.

Furthermore, the confirmatory mean concentrations across the survey areas, provided in Table 3, were compared with the mean concentrations that ORISE calculated from the site's FSS results for each survey unit. The calculated gross site mean concentrations from Cabrera's soil sample data were $0.67 \mathrm{pCi} / \mathrm{g}$ for $\mathrm{Th}-232+\mathrm{C}$ and $1.22 \mathrm{pCi} / \mathrm{g}$ for $\mathrm{U}-238+\mathrm{C}$. These values were comparable to the confirmatory mean concentrations of $0.64 \mathrm{pCi} / \mathrm{g}$ for Th-232 and $1.66 \mathrm{pCi} / \mathrm{g}$ for U-238. These data validated the site's FSS results. Additionally, the independent surveys validated the soil area classifications.

The gross concentrations of the two judgmental soil samples collected in Survey Unit 9 exceeded the DCGL $_{\mathrm{w}}$. After background concentrations are subtracted, both of these samples still exceed the DCGL $_{\mathrm{w}}$; one for Th-232 and the other for U-238. The determination of the DCGL $\mathrm{EMC}_{\mathrm{E}}$ for Sample S025 with an area of $1 \mathrm{~m}^{2}$ provides a DCGL $\mathrm{EMC}_{\mathrm{E}}$ of $32.25 \mathrm{pCi} / \mathrm{g}$ for Th-232 and $45.77 \mathrm{pCi} / \mathrm{g}$ for 
$\mathrm{U}-238$; the sample concentrations are within the EMC values. The determination of the $\mathrm{DCGL}_{\mathrm{EMC}}$ for Sample S026 with an area of $4 \mathrm{~m}^{2}$ provides a $\mathrm{DCGL}_{\mathrm{EMC}}$ of $12.27 \mathrm{pCi} / \mathrm{g}$ for Th-232 and $17.46 \mathrm{pCi} / \mathrm{g}$ for $\mathrm{U}-238$; the sample concentration for $\mathrm{U}-238$ exceeds the EMC value.

\section{SUMMARY}

ORISE performed confirmatory activities for 18 site areas at the DNSC New Haven Depot during the period October 5 through 8, 2009. These activities included the review and assessment of the FSS reports and independent measurements and sampling. The confirmatory survey results indicated that residual activity in excess of the site specific $\mathrm{DCGL}_{\mathbb{W}}$ is present in the following survey units - Soil Survey Unit 9 and Structural Survey Units: SU 145, SU 210-2-1, SU 210-2-3, SU 210-24, SU 210-2-F and SU 8 (Rail Scale).

Of the Class 1 areas (SU 9, SU 210-2-1, SU 210-2-3, and SU 210-2-4), when the elevated measurement comparison (EMC) criteria was applied, soil Survey Unit 9 (specifically soil sample S026) did not meet the EMC criteria. All of the Class 1 structural surfaces met the EMC criteria for alpha activity. However, the elevated gamma radiation and elevated alpha + beta surface activity measurement within a borehole along a crack in SU 210-2-3 demonstrates that residual radioactive contamination remains within this survey unit.

In Cabrera's final status survey report, SU 210-2-F and SU 145-F were classified as Class 3 survey units and SU 8 (Rail Scale) was classified as a Class 2 survey unit. The FSS data results portrayed surface activity levels below the DCGL $\mathrm{W}_{\mathrm{W}}$ for these areas. However, ORISE confirmatory survey activities indicated that alpha surface activity levels within these survey units exceeded the DCGL and that these survey units were incorrectly classified. 


\section{REFERENCES}

Cabrera Services, Inc. (Cabrera). Final Status Survey Report: Defense National Stockpile Center, New Haven Depot. New Haven, IN; Baltimore, MD January 2009.

Oak Ridge Associated Universities (ORAU). Quality Program Manual for the Independent Environmental Assessment and Verification Program. Oak Ridge, TN; June 30, 2009.

Oak Ridge Institute for Science and Education (ORISE). Survey Procedures Manual for the Independent Environmental Assessment and Verification Program. Oak Ridge, TN; May 1, 2008.

Oak Ridge Institute for Science and Education. Final Confirmatory Survey Plan for the Defense Logistics Agency, Defense National Stockpile Center New Haven Depot, New Haven, Indiana. (RFTA No. 09-013; Docket 040-00341), DCN 2001-PL-01-0. Oak Ridge, TN; October 1, 2009 a.

Oak Ridge Institute for Science and Education. Laboratory Procedures Manual for the Independent Environmental Assessment and Verification Program (LAB). Oak Ridge, TN; June 30, $2009 \mathrm{~b}$.

U. S. Environmental Protection Agency (EPA). Guidance on Choosing a Sampling Design for Environmental Data Collection for Use in Developing a Quality Assurance Project Plan, EPA QA/G-5S. Washington, DC; December 2002.

U.S. Nuclear Regulatory Commission (NRC). Minimum Detectable Concentrations with Typical Radiation Survey Instruments for Various Contaminants and Field Conditions. NUREG 1507. Washington, DC; June 1998.

U.S. Nuclear Regulatory Commission. Multi-Agency Radiation Survey and Site Investigation Manual (MARSSIM), NUREG-1575; Revision 1. Washington, DC; August 2000. 
APPENDIX A

FIGURES 


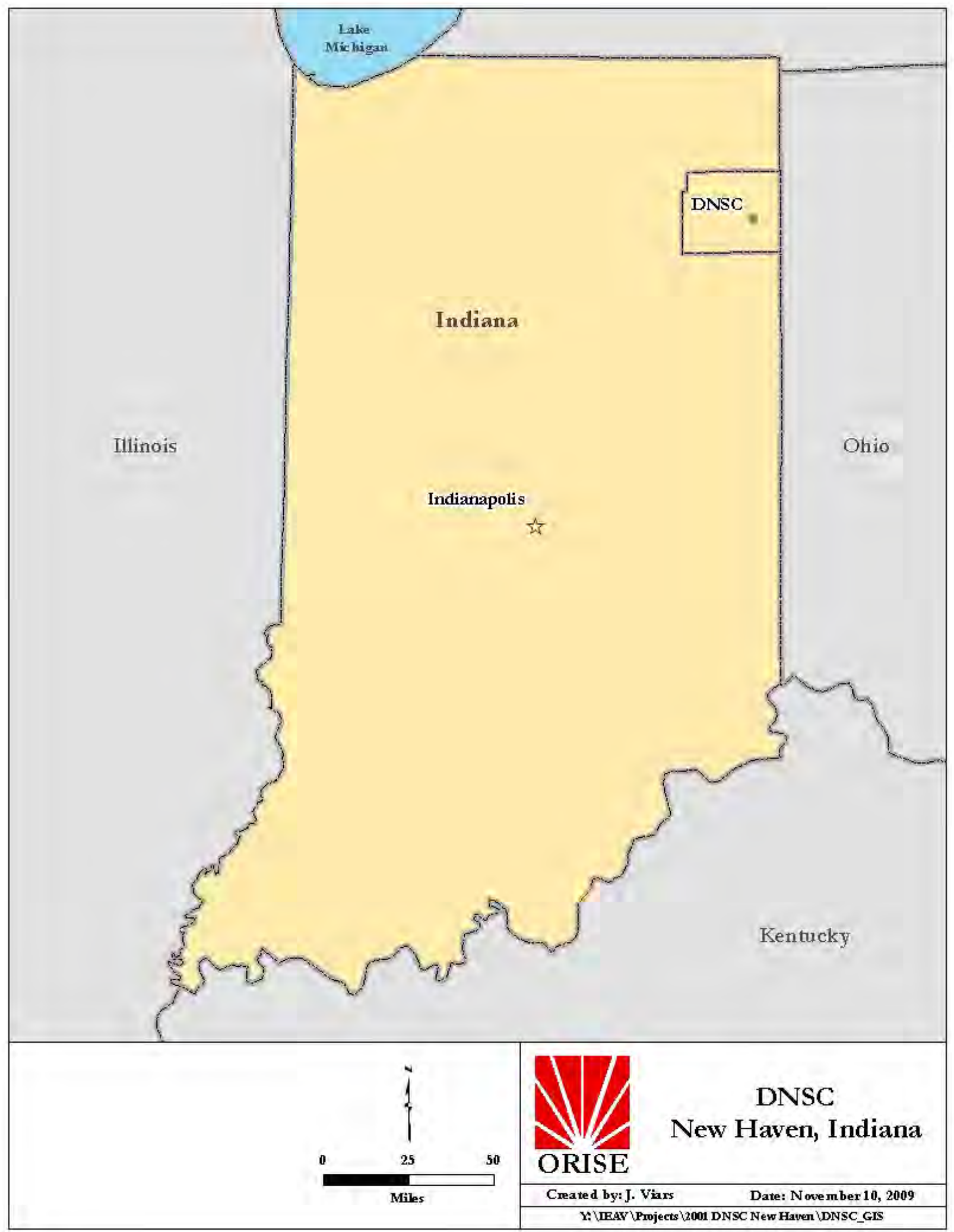

Figure A-1: Location of the DNSC New Haven Depot 


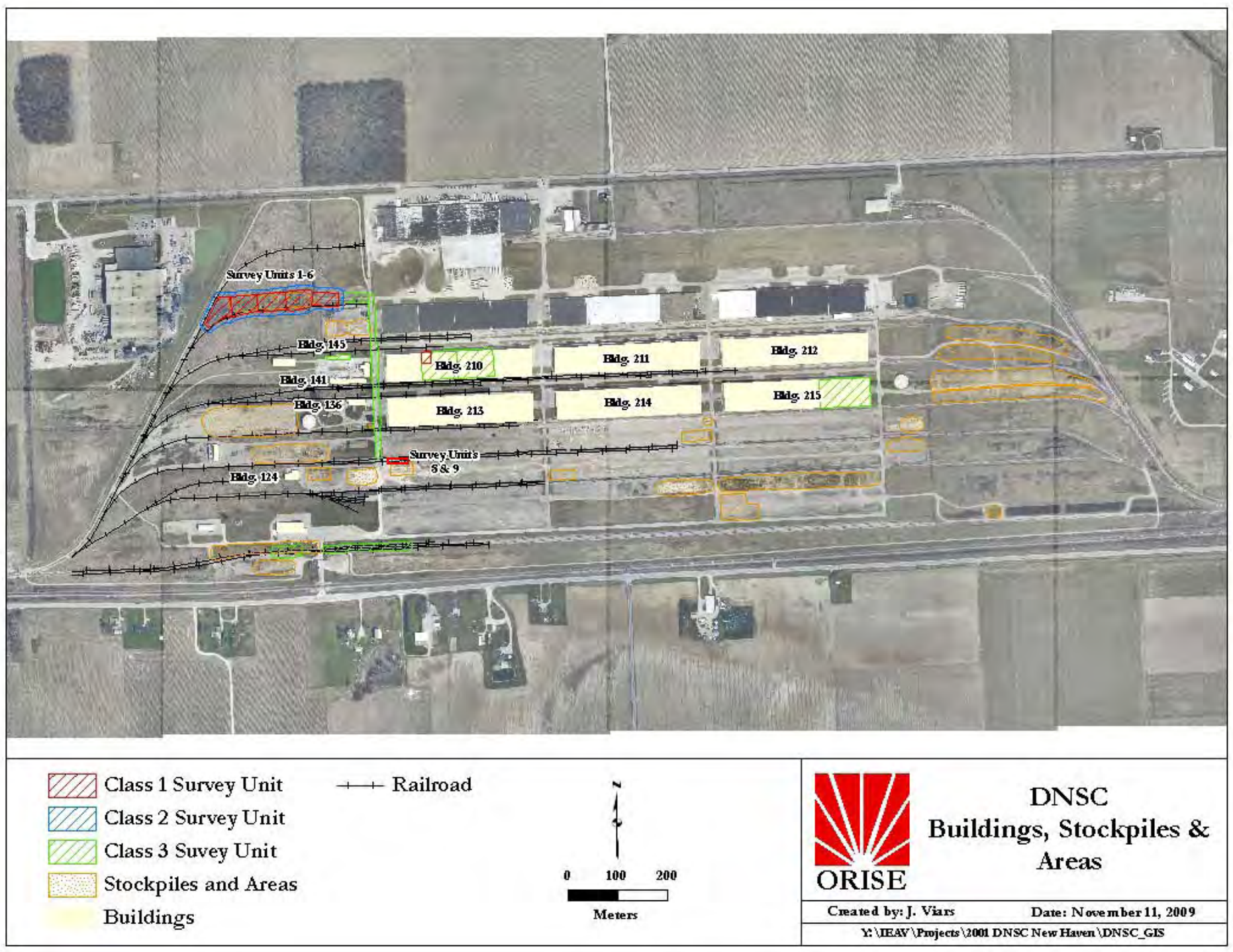

Figure A-2: DNSC New Haven Depot-Buildings, Stockpiles and Areas 


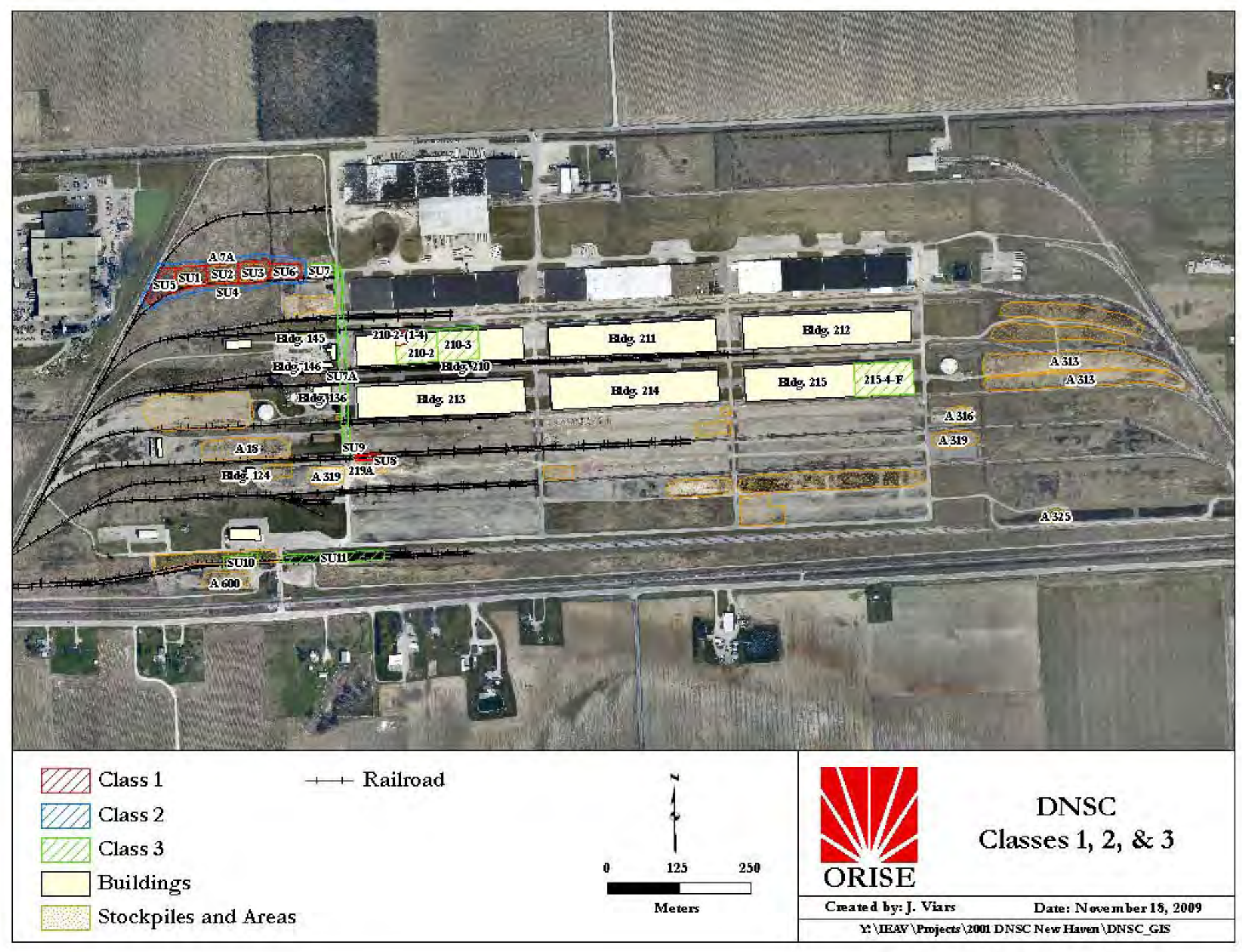

Figure A-3: DNSC New Haven Depot-Outdoor Survey Areas and Survey Unit Classifications 


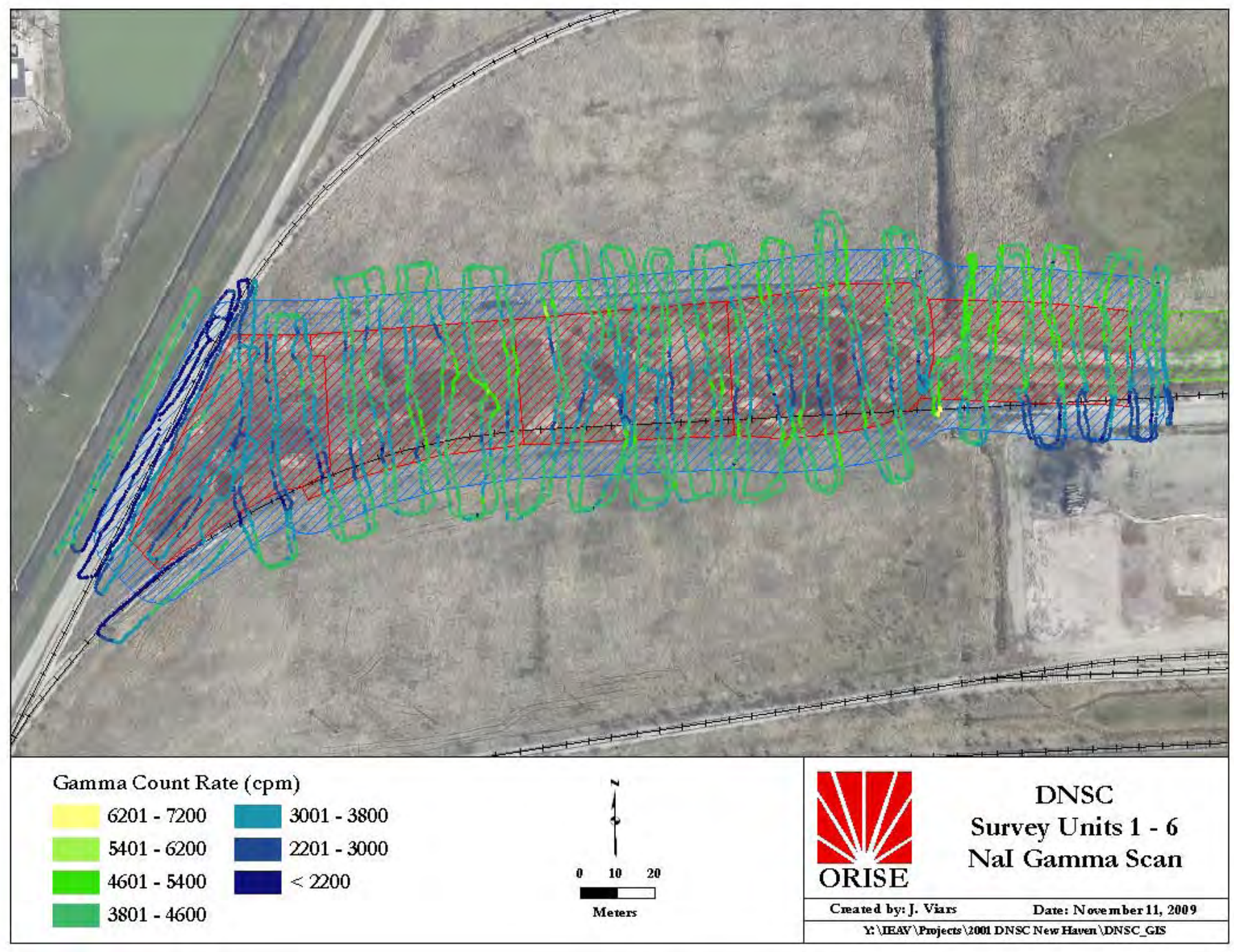

Figure A-4: Survey Units 1-6—Survey Area and Gamma Scans 


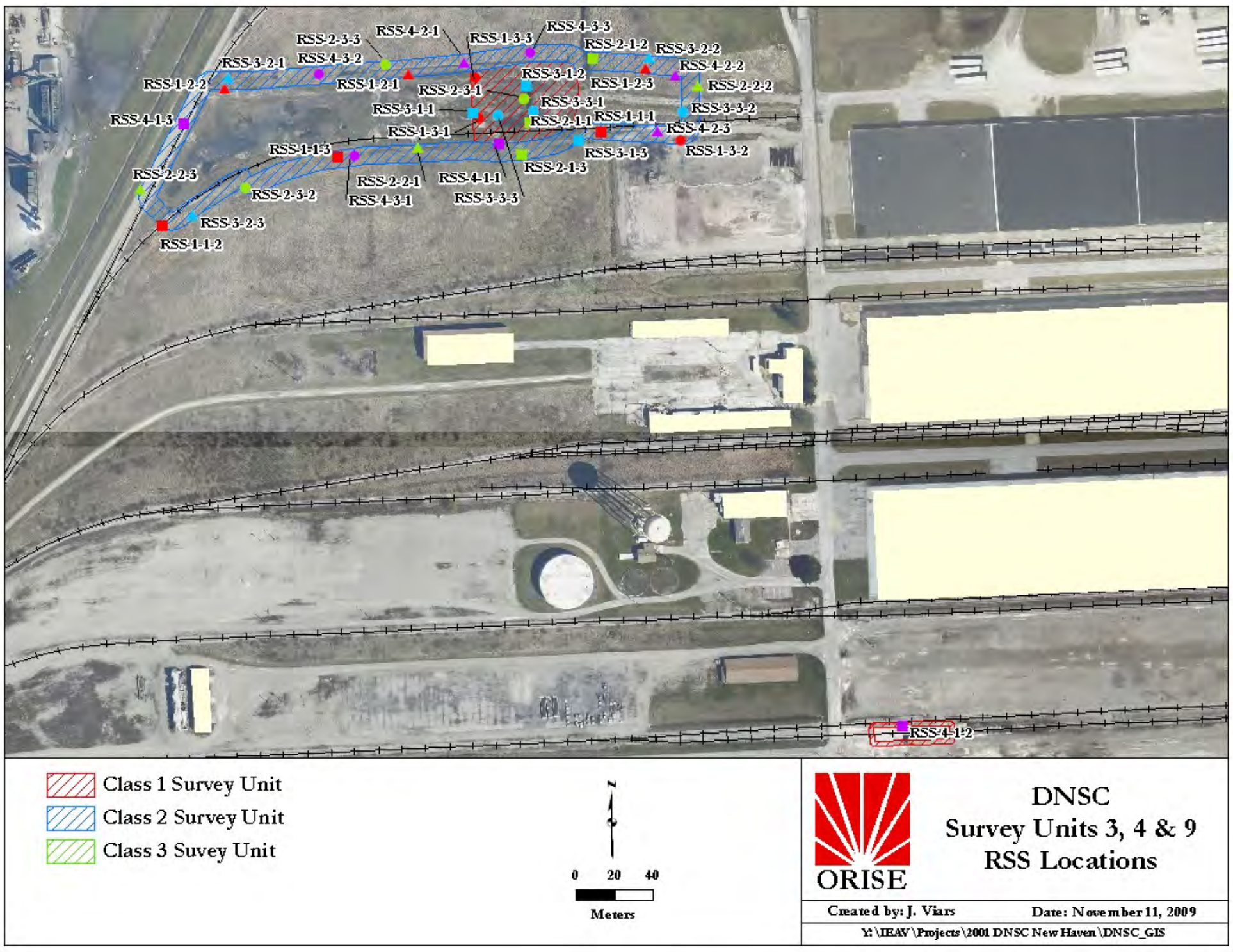

Figure A-5: Group 1 (Survey Units 3, 4 and 9) Confirmation Population, Survey Areas-Ranked Set Sampling Measurement Locations 


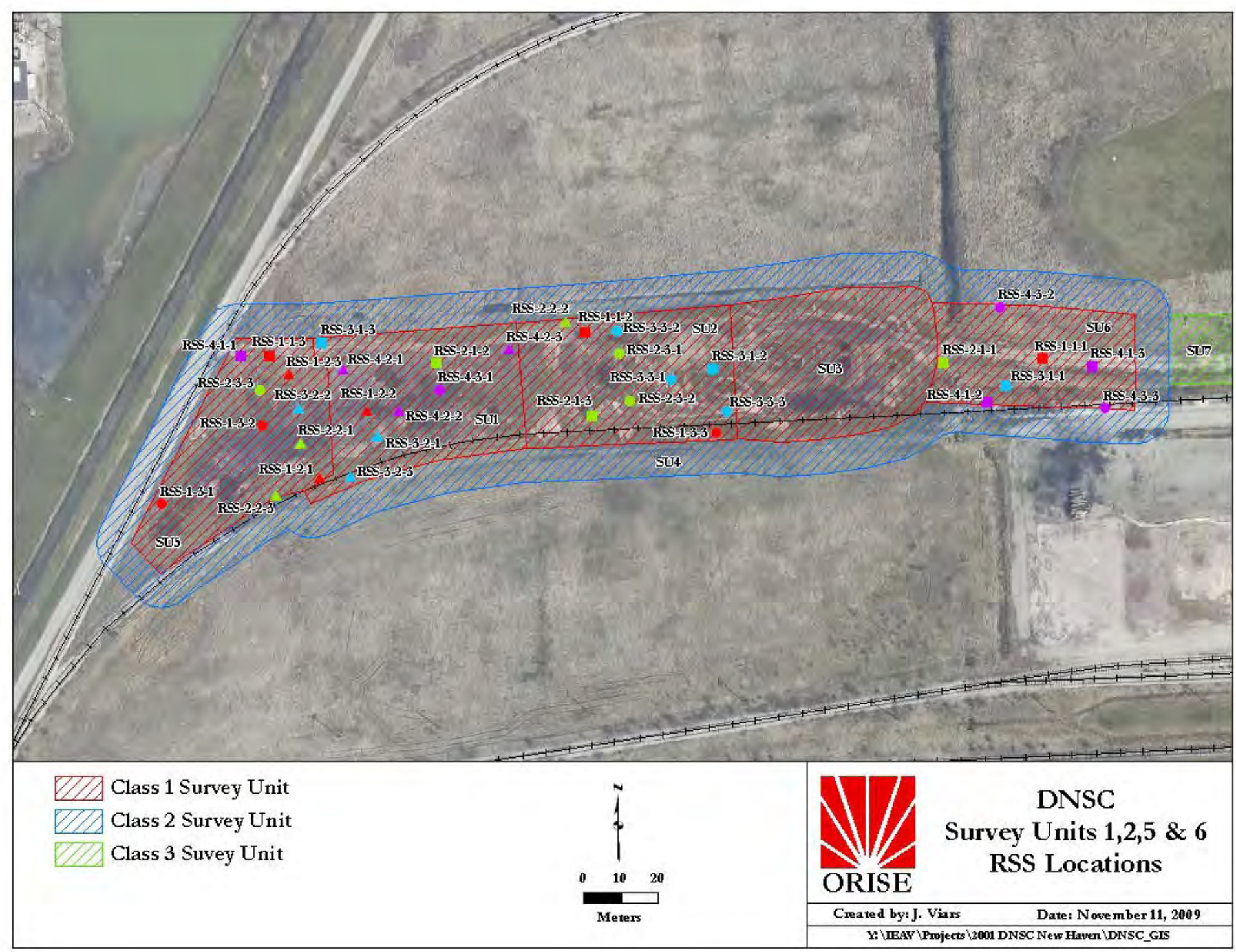

Figure A-6: Group 2 (Survey Units 1, 2, 5 and 6) Confirmation Population, Survey Areas-Ranked Set Sampling Measurement Locations 

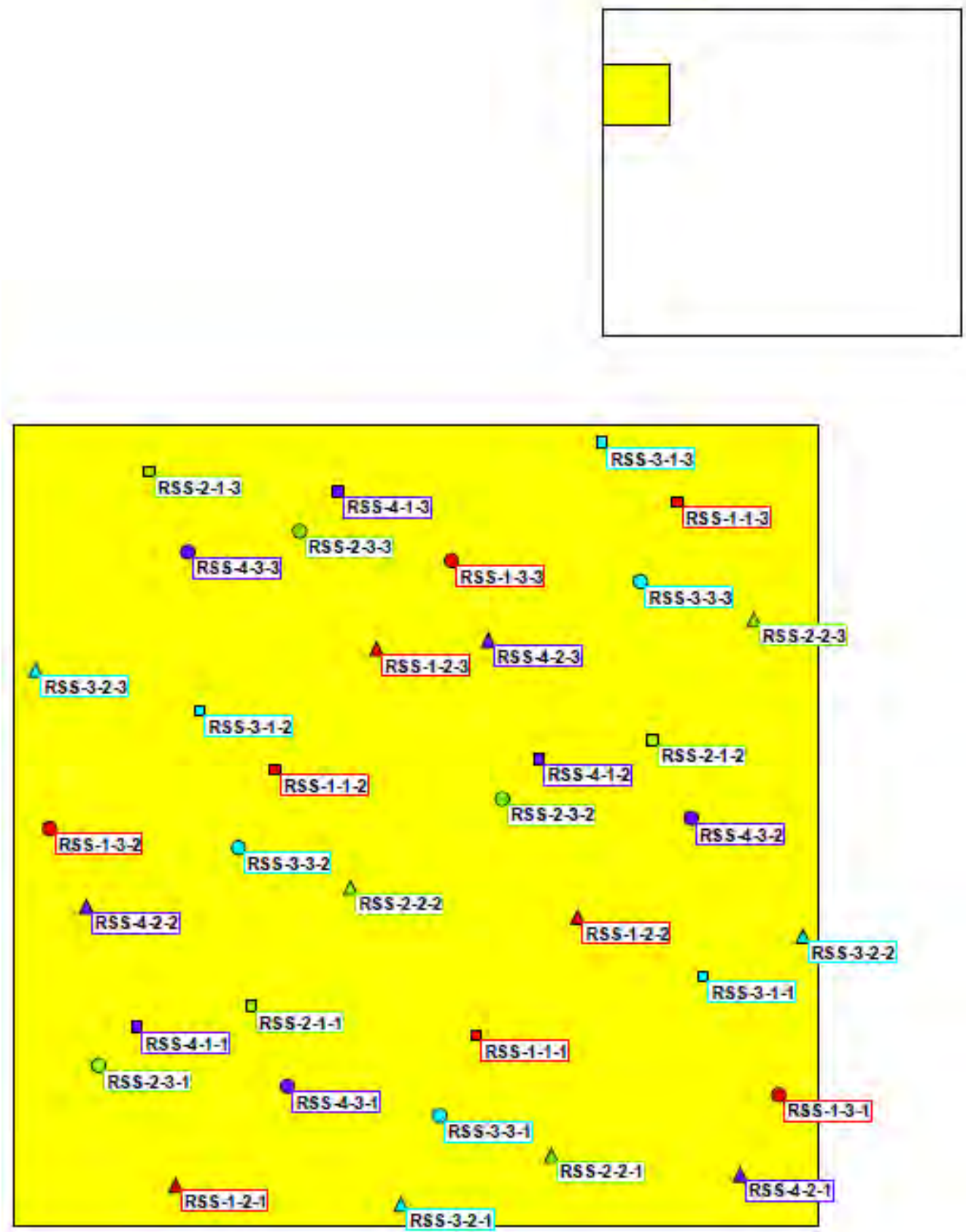

Figure A-7: Group 3 (Survey Unit 210, Section 2, Area 6) Confirmation Population, Survey Areas-Ranked Set Sampling Measurement Locations 


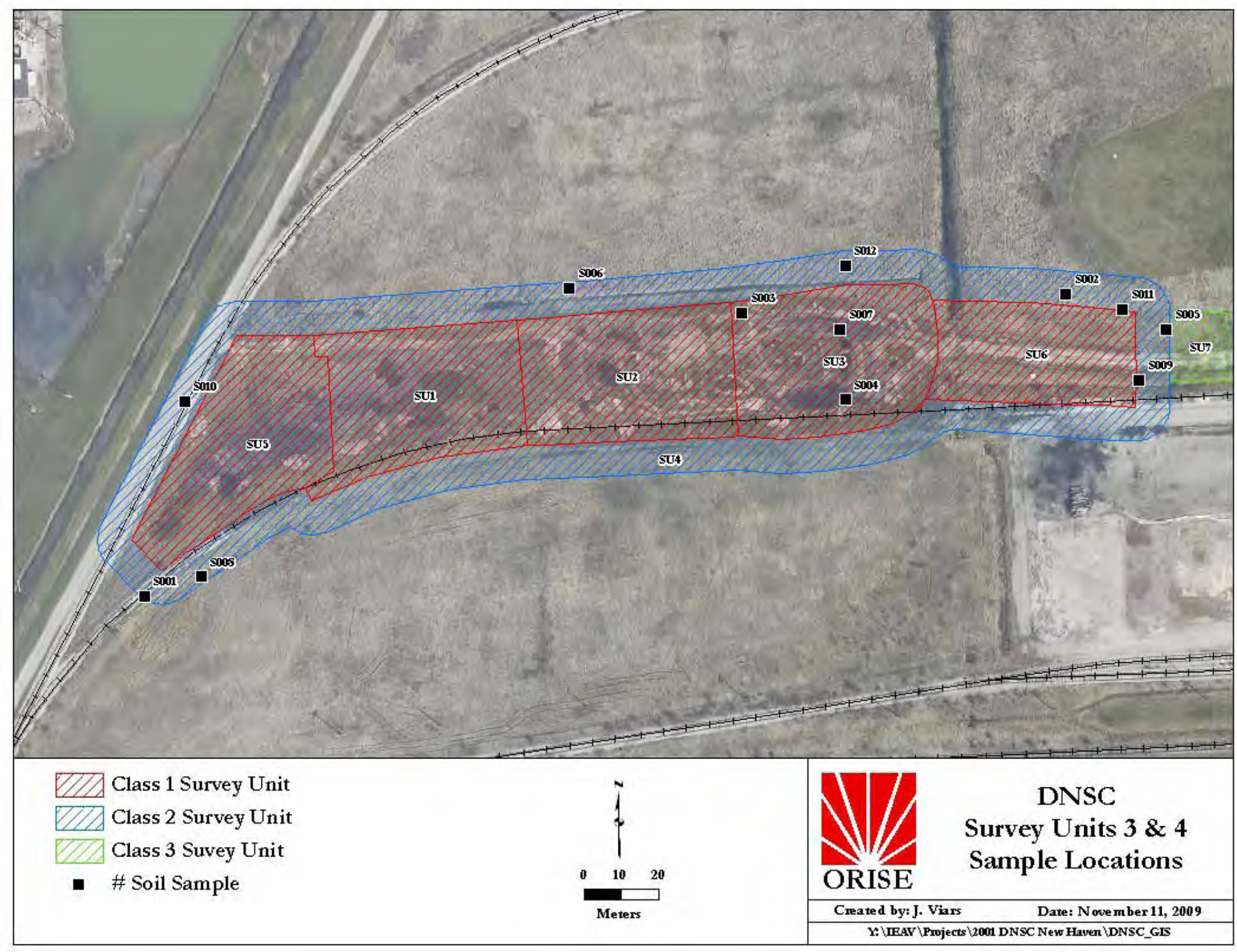

Figure A-8: Group 1 (Survey Units 3 and 4) Confirmation Population, Survey Areas-Soil Sampling Locations 


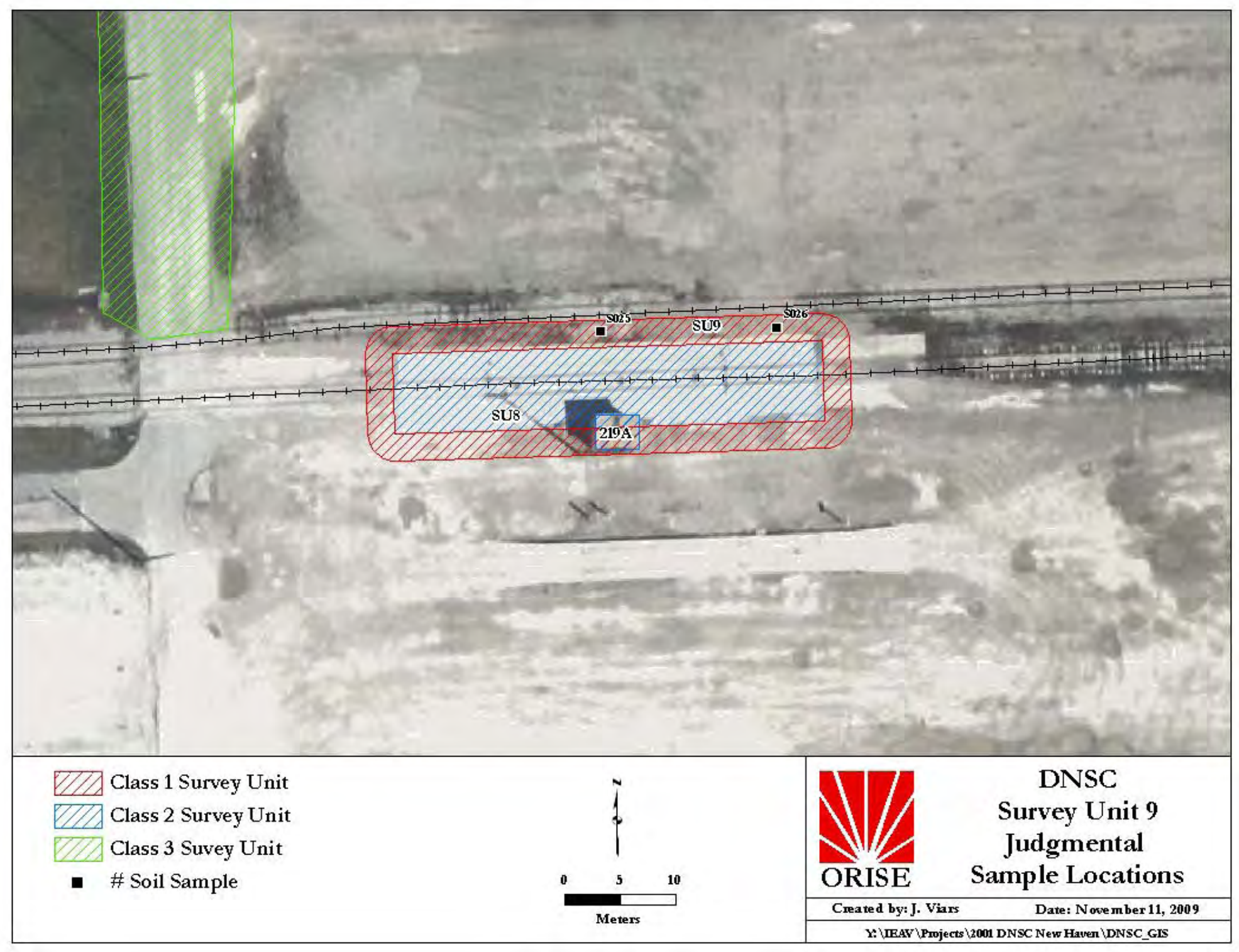

Figure A-9: Group 1 (Survey Unit 9) Confirmation Population, Survey Areas-Judgmental Soil Sampling Locations 


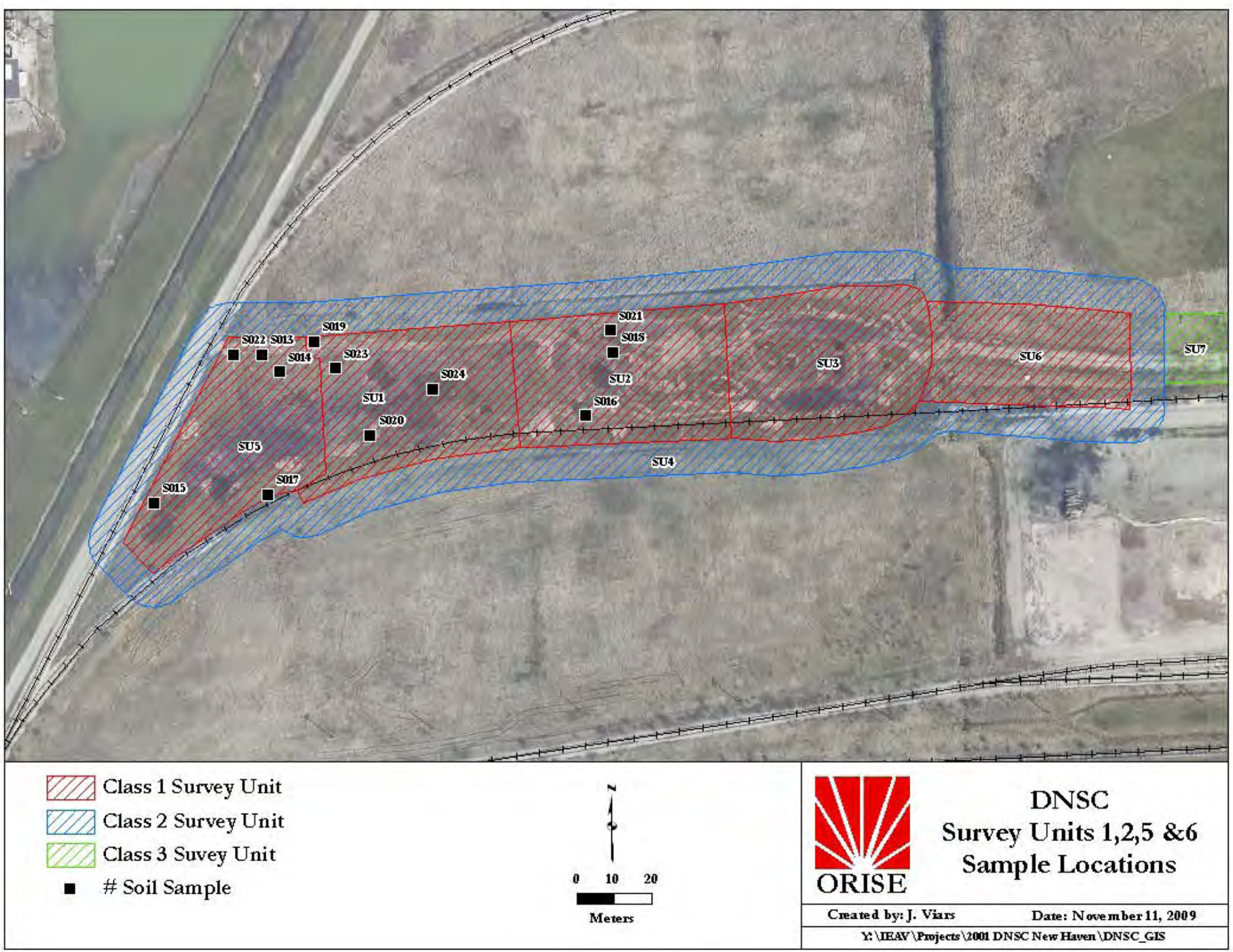

Figure A-10: Group 2 (Survey Units 1, 2, 5 and 6) Confirmation Population, Survey Areas-Soil Sampling Locations 

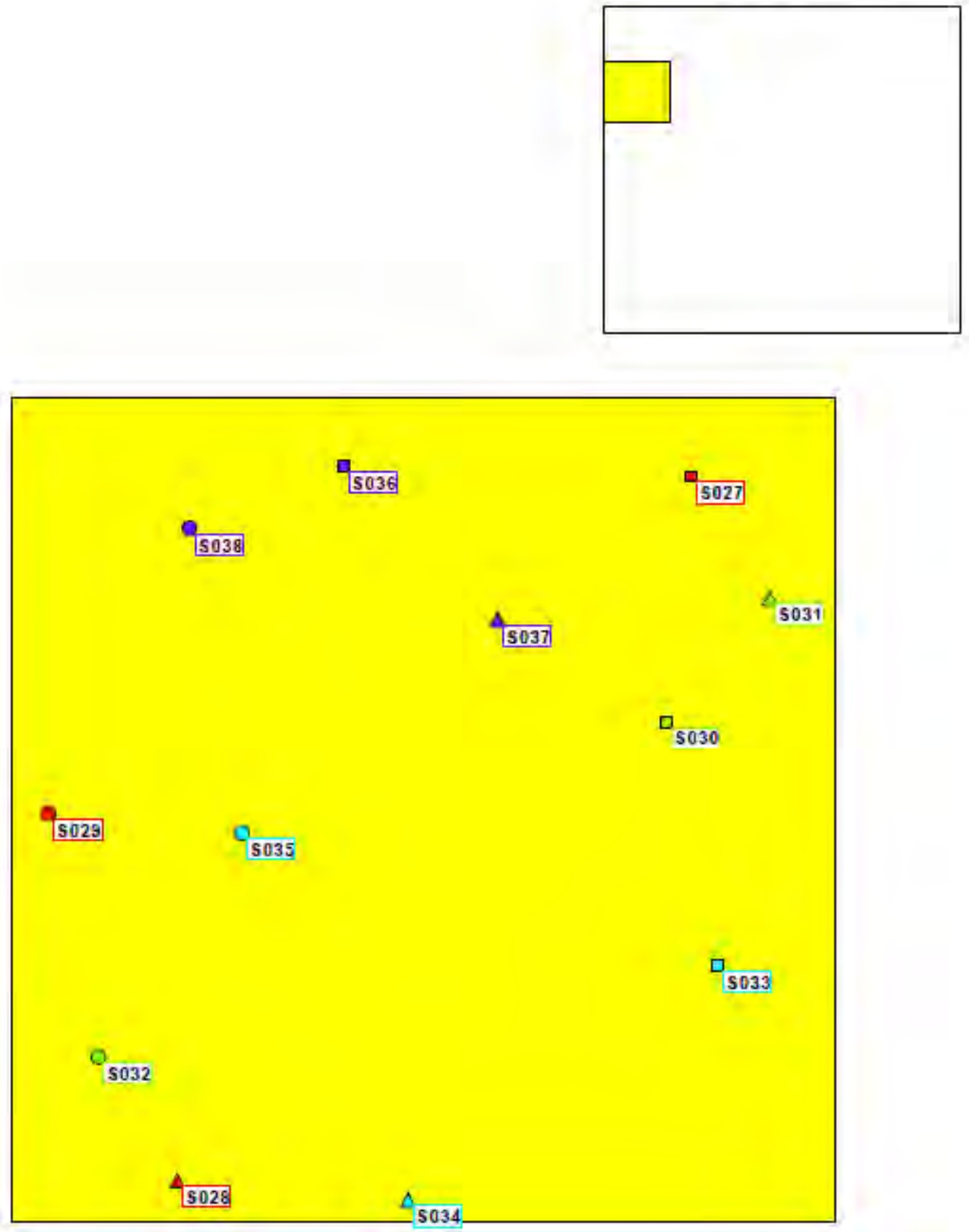

Figure A-11: Group 3 (Survey Unit 210, Section 2, Area 6) Confirmation Population, Survey Areas-Soil Sampling Locations 


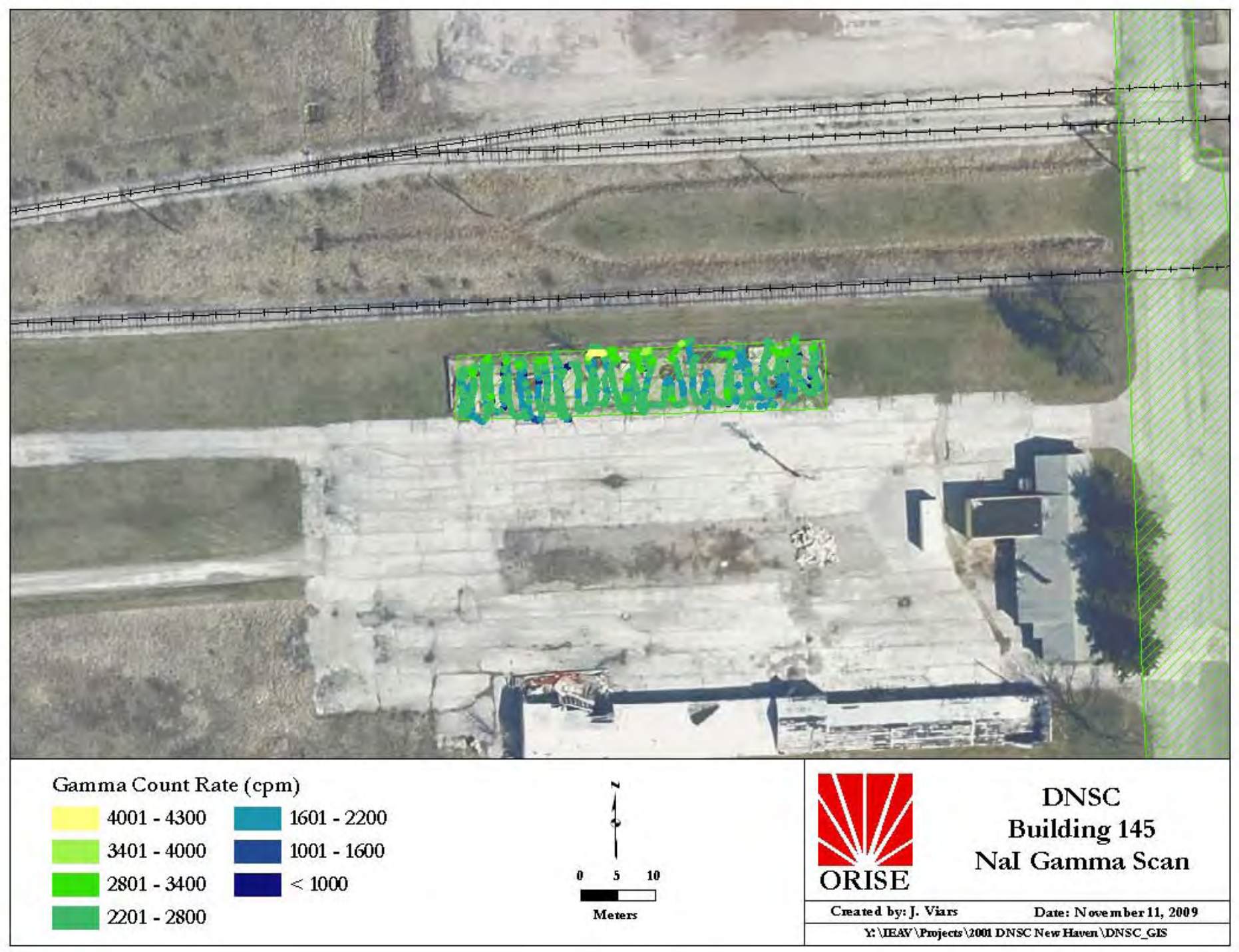

Figure A-12: Survey Unit 145—Survey Area and Gamma Scans 


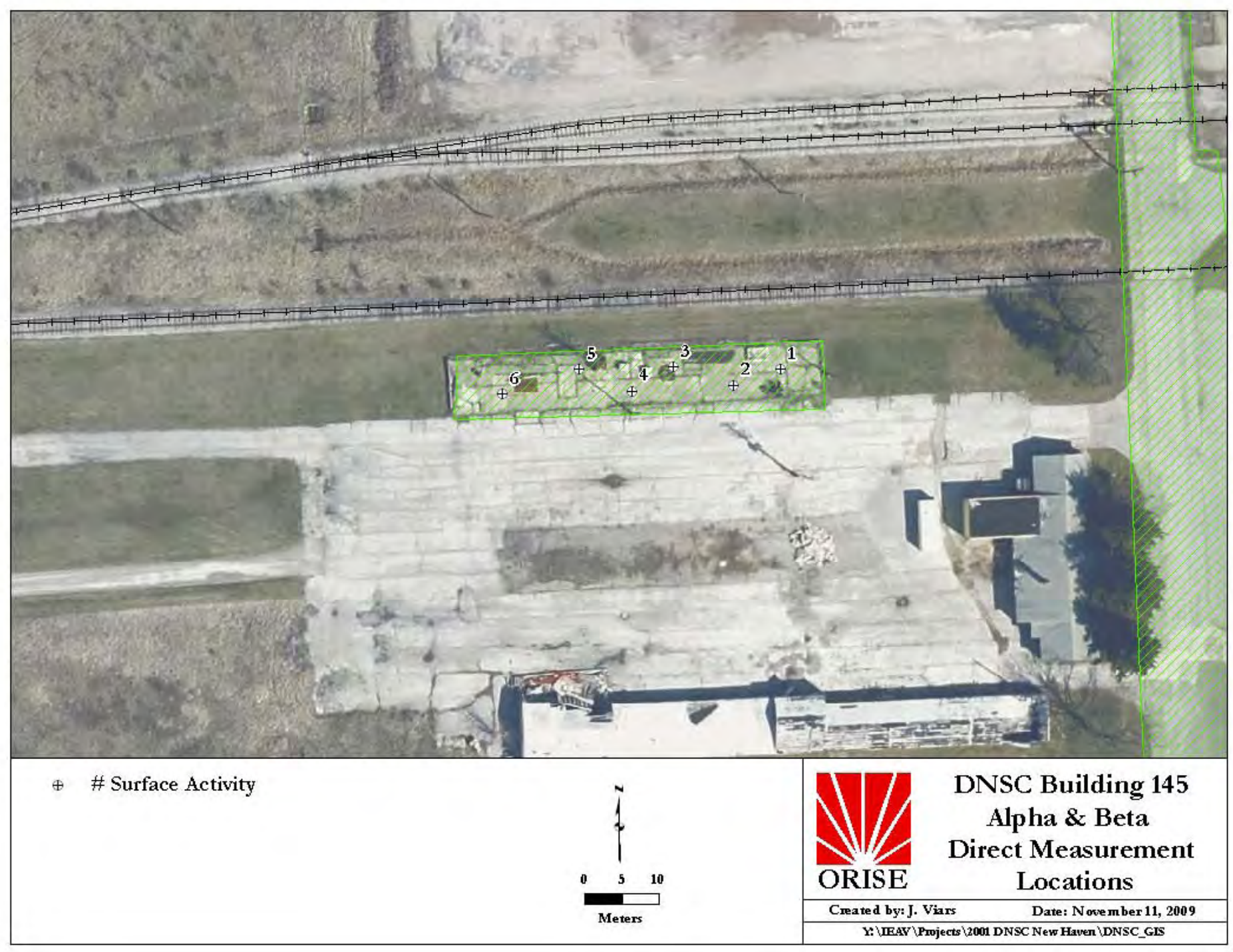

Figure A-13: Survey Unit 145-Direct Measurement Locations 


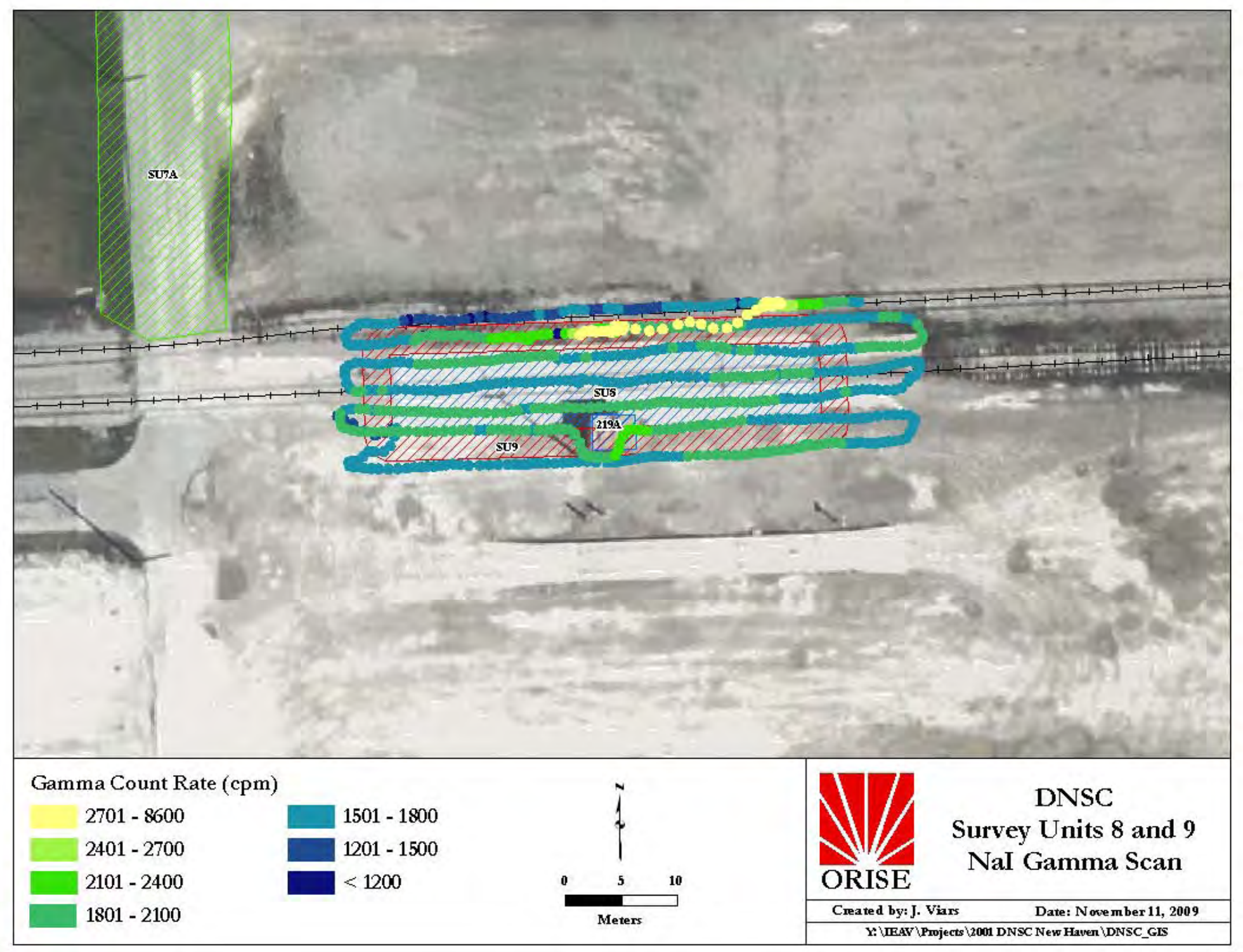

Figure A-14: Survey Units 8 and 9-Survey Area and Gamma Scans 


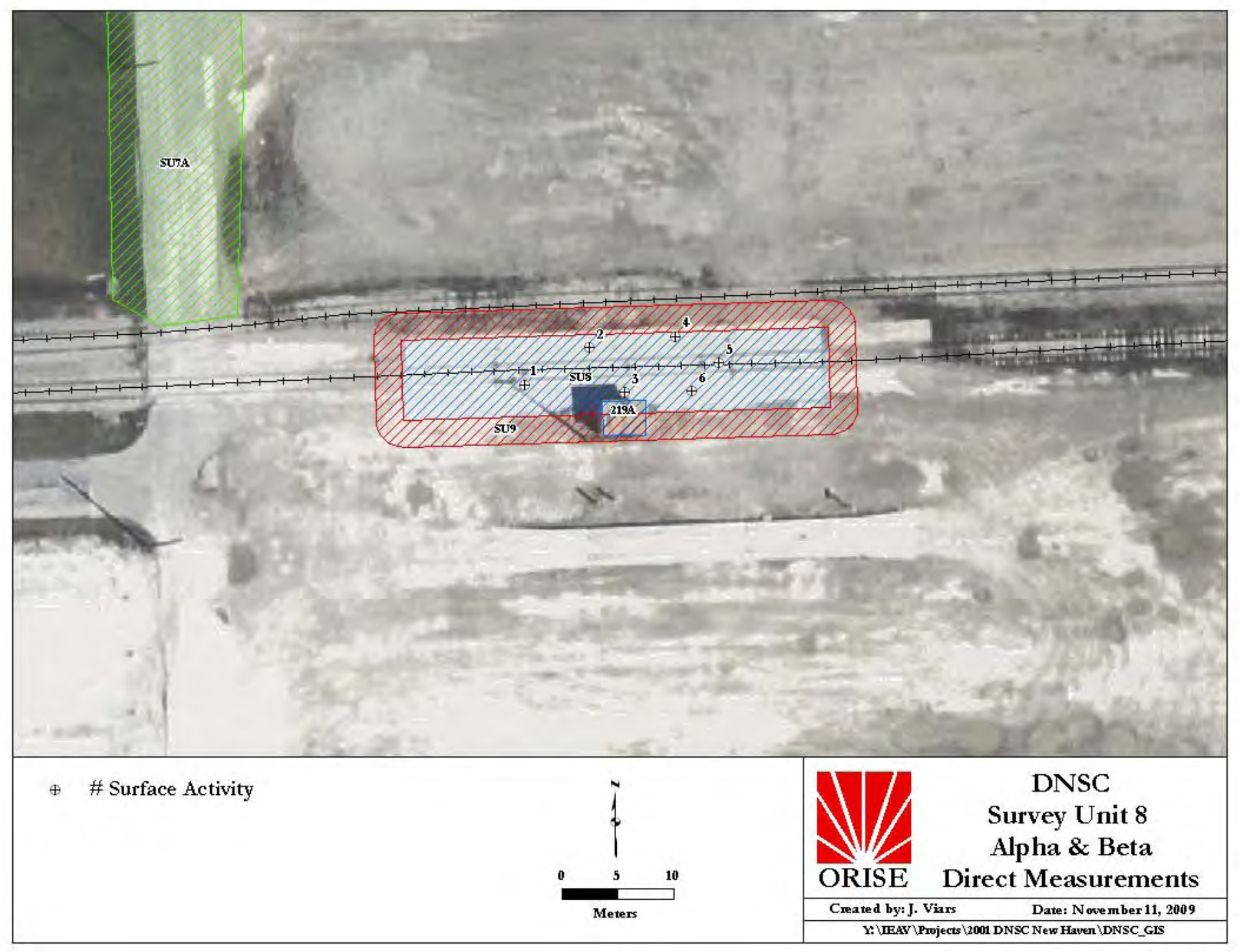

Figure A-15: Survey Unit 8, Rail Scale-Direct Measurement Locations 


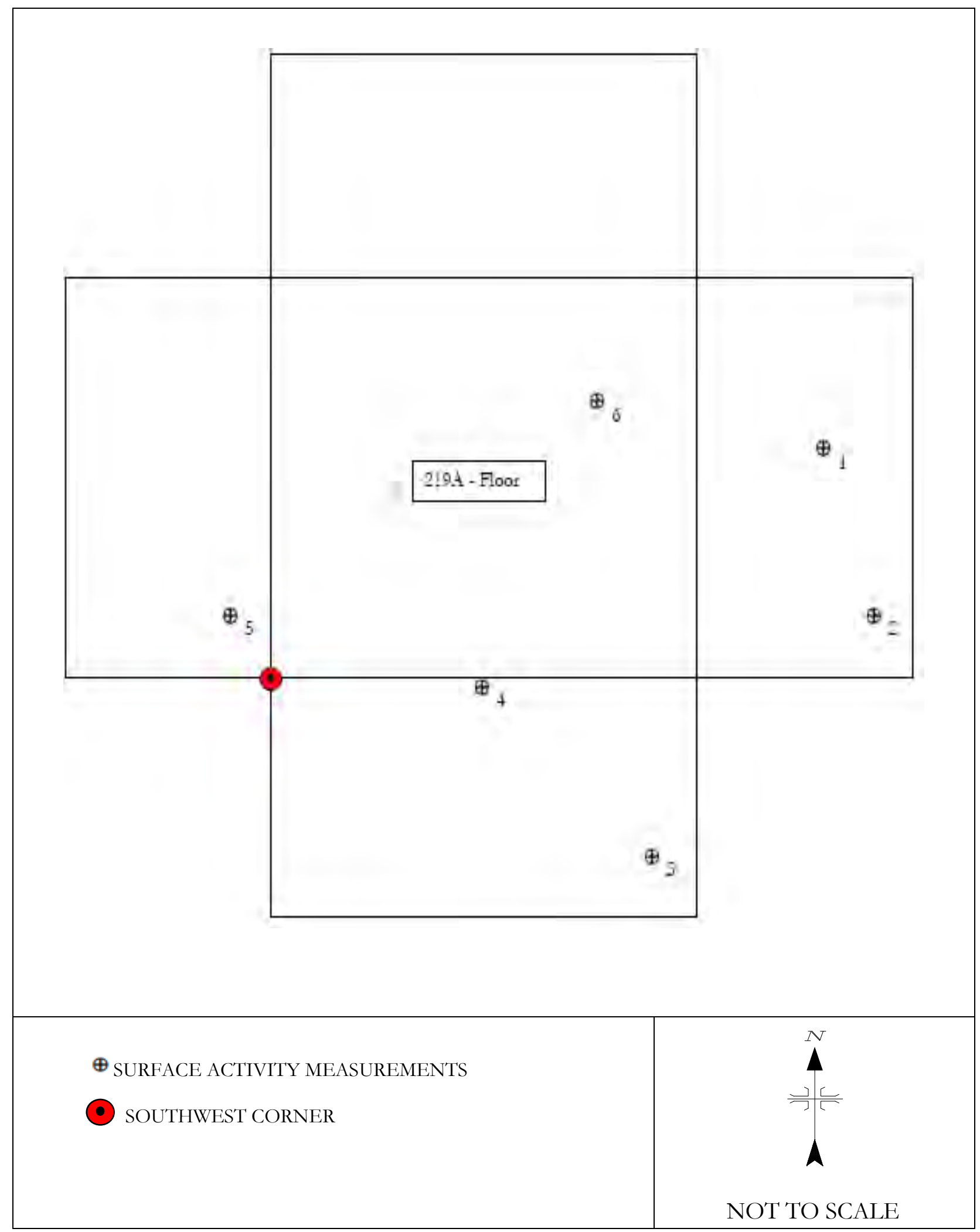

Figure A-16: Survey Unit 219A—Direct Measurement Locations 


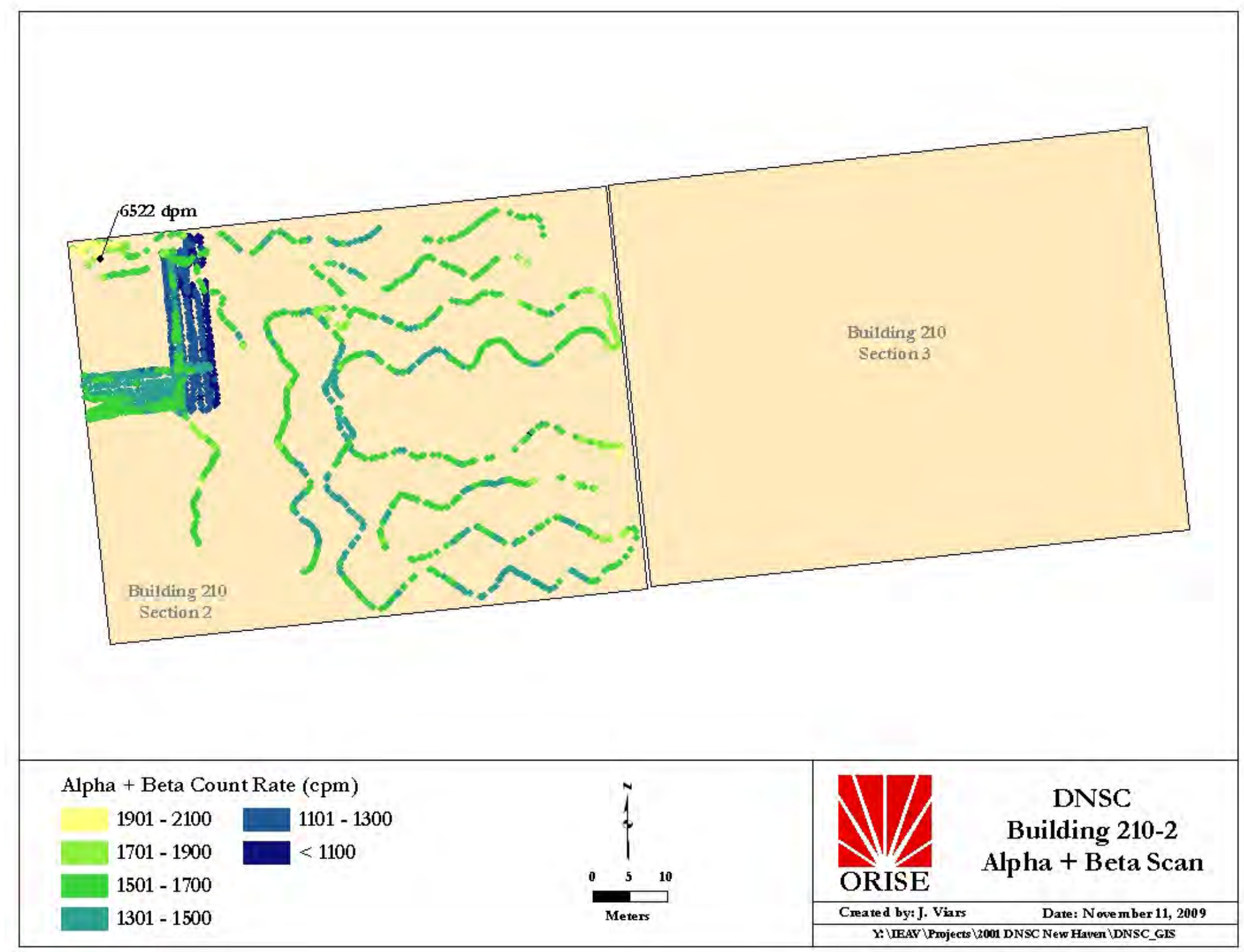

Figure A-17: Building 210 Section 2-Survey Area and Alpha plus Beta Scans 


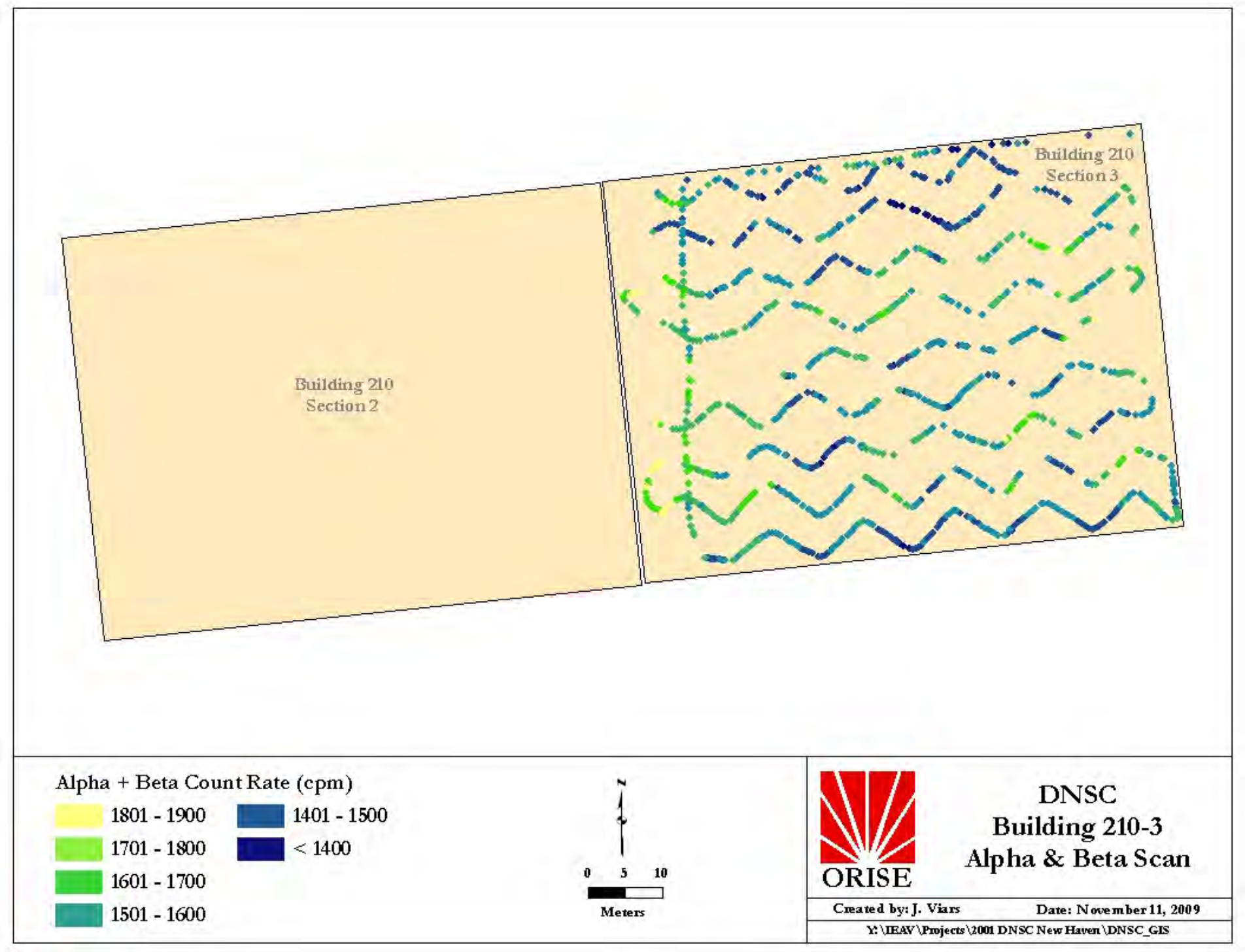

Figure A-18: Building 210 Section 3-Survey Area and Alpha plus Beta Scans 


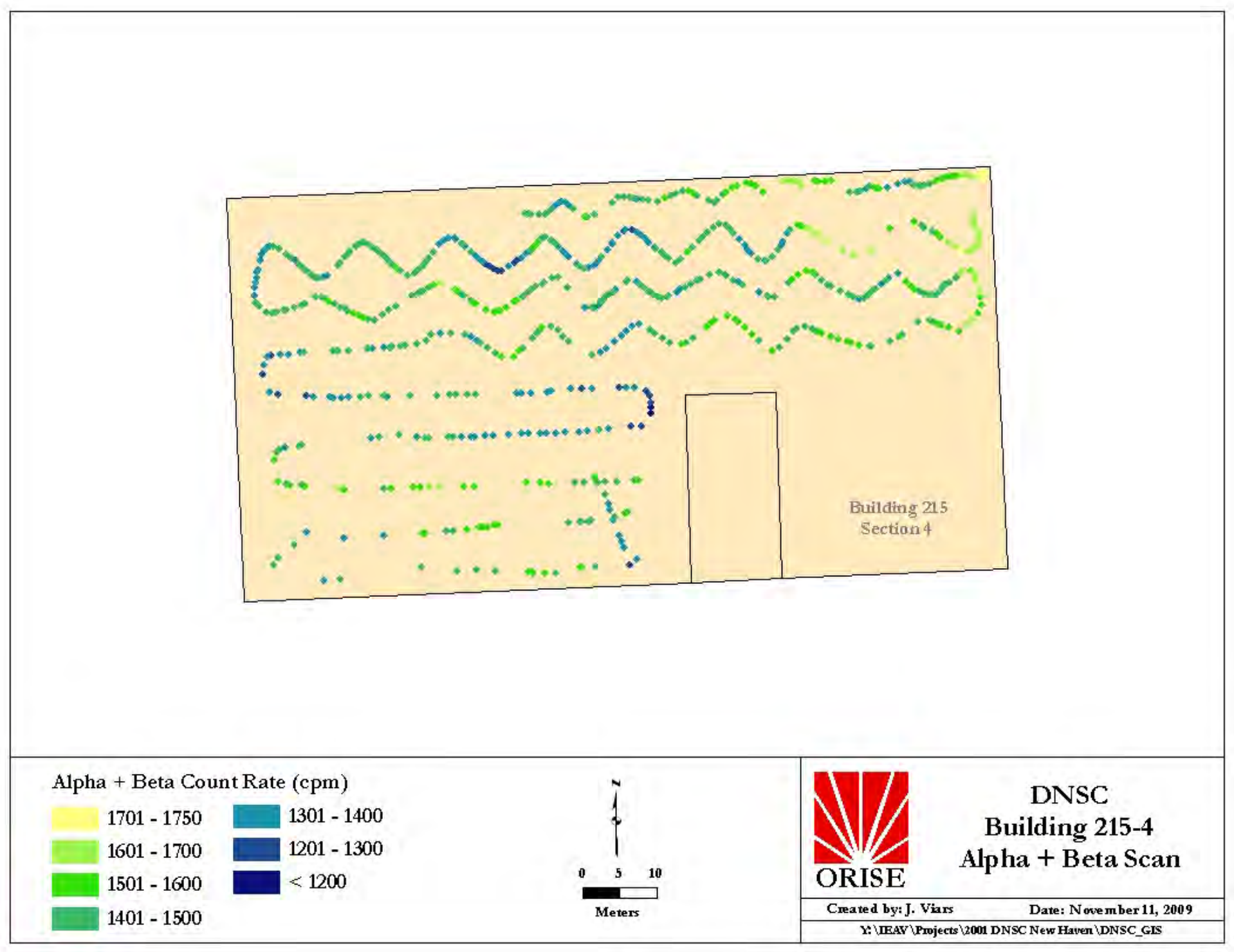

Figure A-19: Building 215 Section 4-Survey Area and Alpha plus Beta Scans 


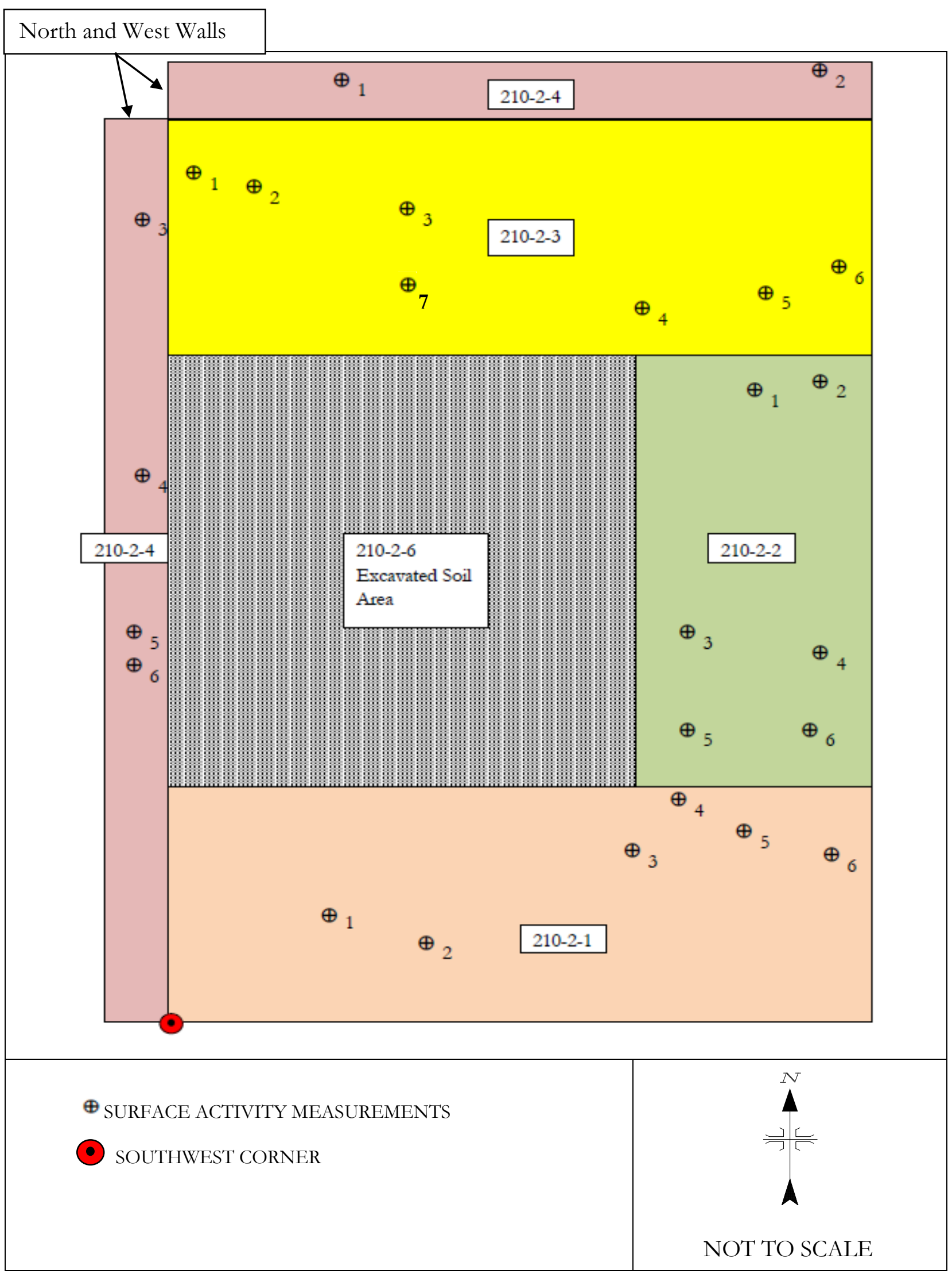

Figure A-20: Building 210 Section 2 Class 1 Survey Units-Direct Measurement Locations 


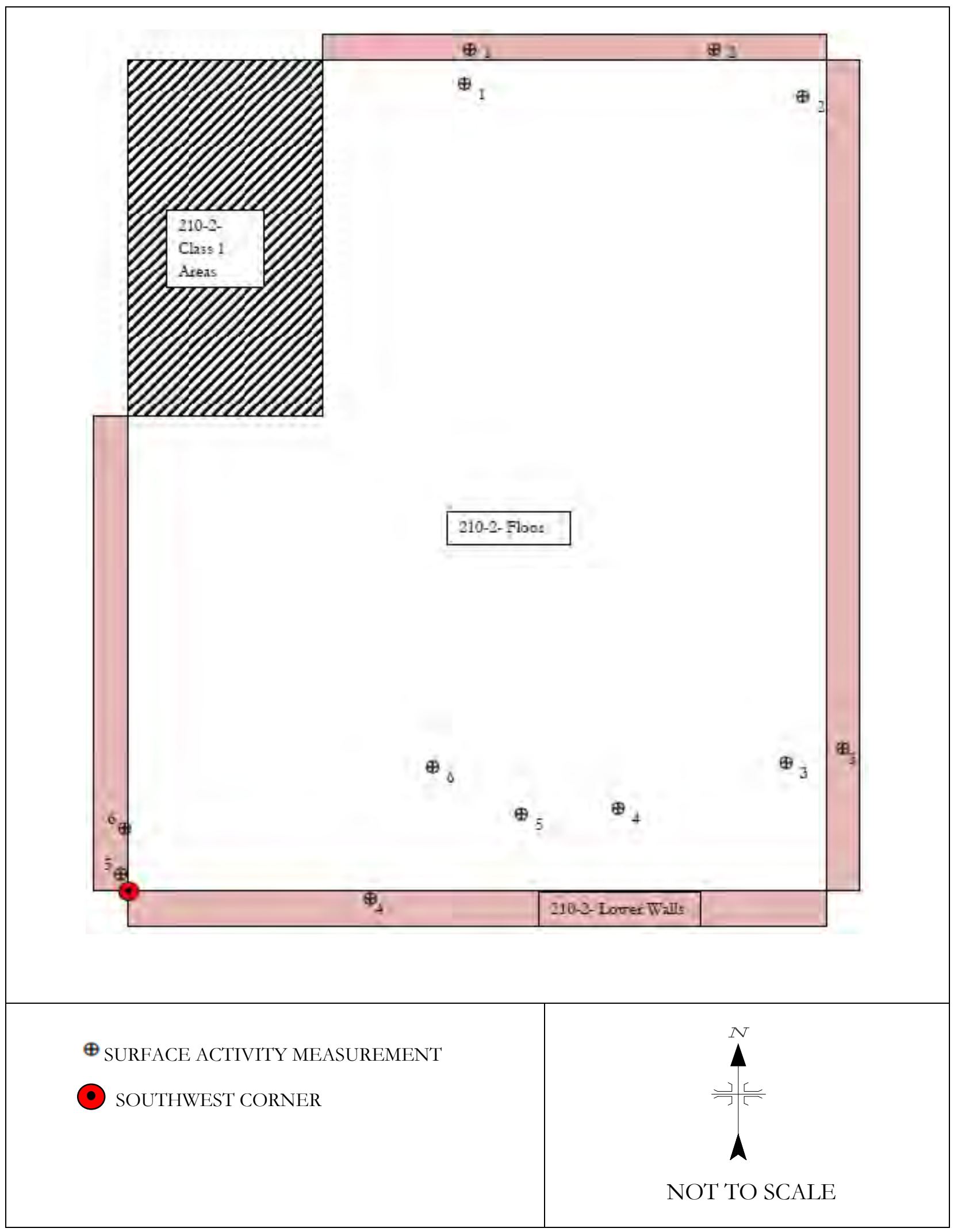

Figure A-21: Building 210 Section 2 Floor and Walls-Direct Measurement Locations 


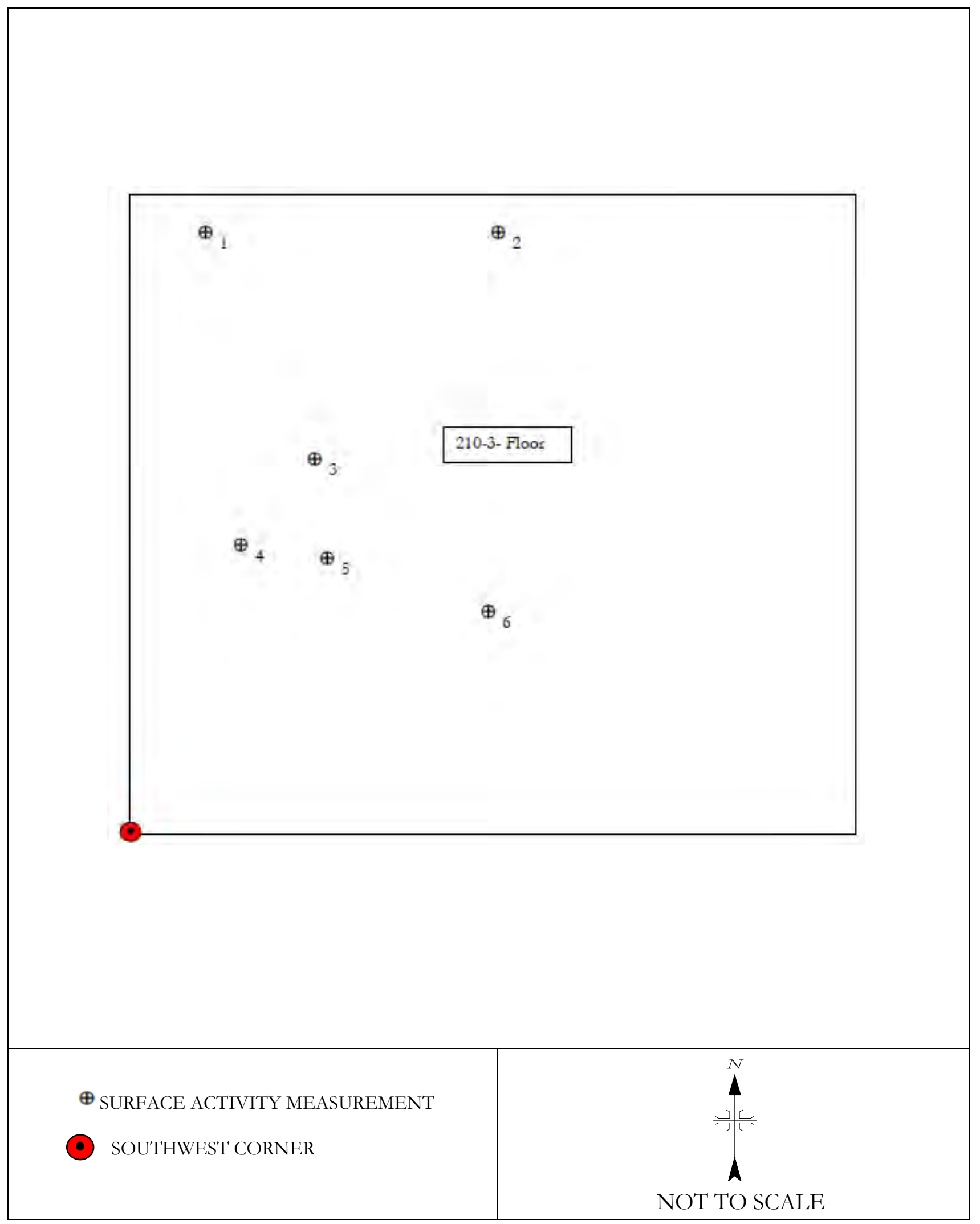

Figure A-22: Building 210 Section 3 Floor-Direct Measurement Locations 


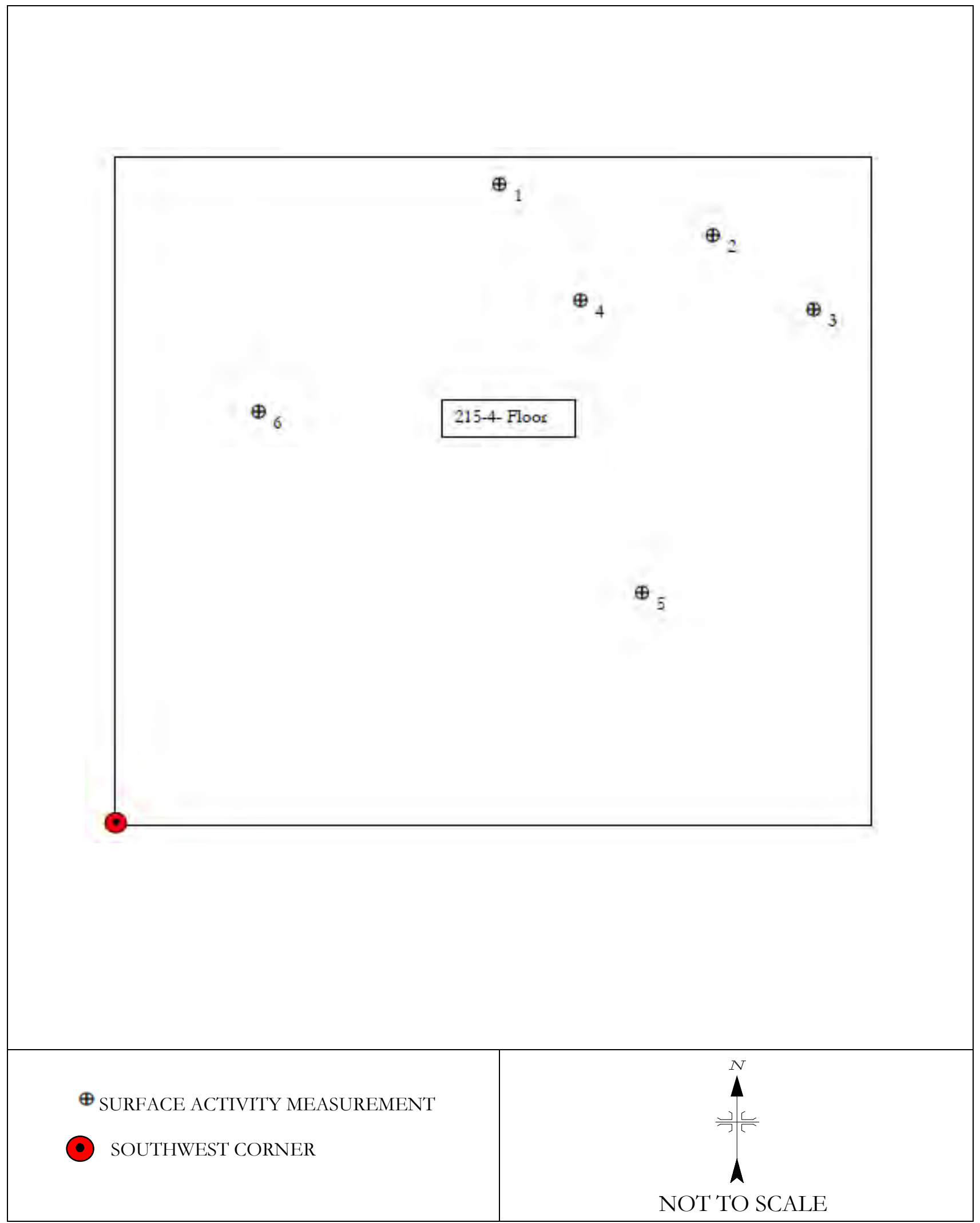

Figure A-23: Building 215 Section 4-Direct Measurement Locations 


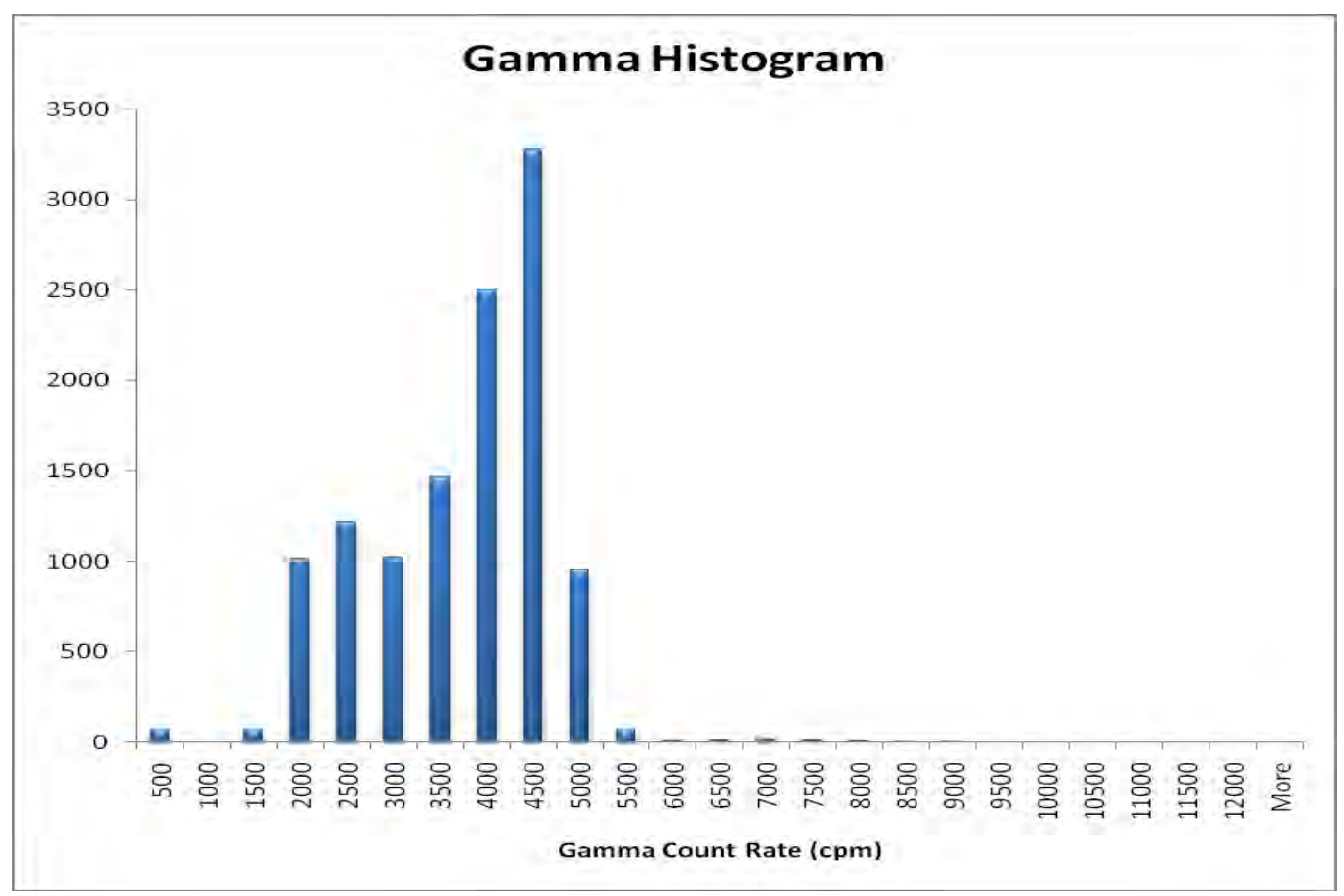

Figure A-24: Verification Outdoor Gamma Scan Count Rate Histogram (Combined Data)

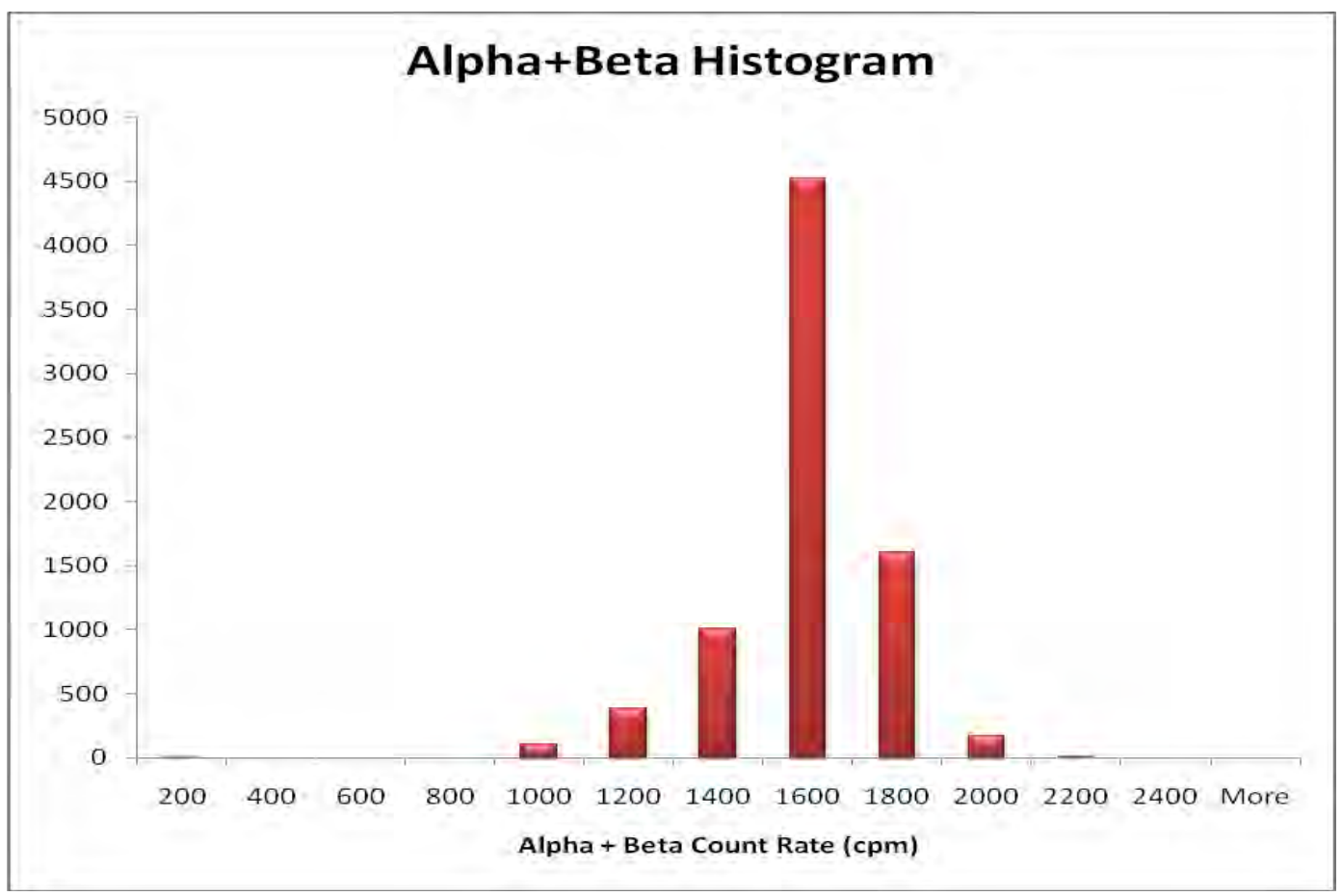

Figure A-25: Verification Indoor Alpha plus Beta Scan Count Rate Histogram (Combined Data) 


\section{APPENDIX B}

\section{TABLES}




\begin{tabular}{|c|c|c|c|c|c|c|}
\hline \multicolumn{7}{|c|}{$\begin{array}{c}\text { TABLE B-1: } \\
\text { RANKED SET SAMPLING GAMMA MEASUREMENTS } \\
\text { DEFENSE NATIONAL STOCKPILE CENTER NEW HAVEN DEPOT } \\
\text { NEW HAVEN, INDIANA }\end{array}$} \\
\hline \multicolumn{3}{|c|}{ Location } & \multirow{2}{*}{$\begin{array}{l}\text { Ranked Set } \\
\text { Sampling }\end{array}$} & \multirow{2}{*}{$\begin{array}{l}\text { Sample Select } \\
\begin{array}{c}\mathrm{L}=\text { Low } \\
\text { M=Medium } \\
\text { H=High }\end{array}\end{array}$} & \multirow{2}{*}{$\begin{array}{c}\text { Sample } \\
\text { ID }^{a, b}\end{array}$} & \multirow{2}{*}{$\begin{array}{c}\text { Gamma } \\
(\mathrm{cpm}) \\
\text { Before }\end{array}$} \\
\hline Area & Northing/X & Easting/Y & & & & \\
\hline \multicolumn{7}{|c|}{ Group 1 (Survey Units 3, 4, 9) } \\
\hline SU349 & 2123858 & 525627 & $1-1-1$ & & & 3933 \\
\hline SU349 & 2123700 & 524889 & $1-1-2$ & $\mathbf{L}$ & 2001S001 & 2917 \\
\hline SU349 & 2123815 & 525185 & $1-1-3$ & & & 5056 \\
\hline SU349 & 2123954 & 525303 & $1-2-1$ & & & 5726 \\
\hline SU349 & 2123931 & 524993 & $1-2-2$ & & & 4236 \\
\hline SU349 & 2123966 & 525701 & $1-2-3$ & $\mathbf{M}$ & 2001S002 & 5057 \\
\hline SU349 & 2123882 & 525422 & $1-3-1$ & & & 3676 \\
\hline SU349 & 2123842 & 525760 & $1-3-2$ & & & 3068 \\
\hline SU349 & 2123950 & 525416 & $1-3-3$ & $\mathbf{H}$ & 2001S003 & 4818 \\
\hline SU349 & 2123873 & 525507 & $2-1-1$ & $\mathbf{L}$ & 2001S004 & 3481 \\
\hline SU349 & 2123981 & 525613 & $2-1-2$ & & & 4467 \\
\hline SU349 & 2123819 & 525495 & $2-1-3$ & & & 5130 \\
\hline SU349 & 2123831 & 525317 & $2-2-1$ & & & 5368 \\
\hline SU349 & 2123935 & 525790 & $2-2-2$ & $\mathbf{M}$ & $2001 S 005$ & 4997 \\
\hline SU349 & 2123761 & 524851 & $2-2-3$ & & & 2711 \\
\hline SU349 & 2123914 & 525497 & $2-3-1$ & & & 4110 \\
\hline SU349 & 2123763 & 525028 & $2-3-2$ & & & 4919 \\
\hline SU349 & 2123972 & 525264 & $2-3-3$ & $\mathbf{H}$ & 2001S006 & 5148 \\
\hline SU349 & 2123889 & 525411 & $3-1-1$ & & & 5354 \\
\hline SU349 & 2123935 & 525502 & $3-1-2$ & $\mathbf{L}$ & $2001 S 007$ & 4894 \\
\hline SU349 & 2123844 & 525589 & $3-1-3$ & & & 6887 \\
\hline SU349 & 2123948 & 524998 & $3-2-1$ & & & 4777 \\
\hline SU349 & 2123983 & 525707 & $3-2-2$ & & & 5032 \\
\hline SU349 & 2123717 & 524939 & $3-2-3$ & $\mathbf{M}$ & 2001S008 & 4784 \\
\hline SU349 & 2123894 & 525514 & $3-3-1$ & & & 3494 \\
\hline SU349 & 2123891 & 525766 & $3-3-2$ & $\mathbf{H}$ & 2001S009 & 4418 \\
\hline SU349 & 2123886 & 525454 & $3-3-3$ & & & 3676 \\
\hline SU349 & 2123836 & 525456 & $4-1-1$ & & & 6333 \\
\hline SU349 & 2122857 & 526134 & $4-1-2$ & & & 3003 \\
\hline SU349 & 2123871 & 524924 & $4-1-3$ & $\mathbf{L}$ & 2001S010 & 2965 \\
\hline SU349 & 2123975 & 525397 & $4-2-1$ & & & 5133 \\
\hline
\end{tabular}




\begin{tabular}{|c|c|c|c|c|c|c|}
\hline \multicolumn{7}{|c|}{$\begin{array}{c}\text { TABLE B-1: } \\
\text { RANKED SET SAMPLING GAMMA MEASUREMENTS } \\
\text { DEFENSE NATIONAL STOCKPILE CENTER NEW HAVEN DEPOT } \\
\text { NEW HAVEN, INDIANA }\end{array}$} \\
\hline \multicolumn{3}{|c|}{ Location } & \multirow{2}{*}{$\begin{array}{l}\text { Ranked Set } \\
\text { Sampling }\end{array}$} & \multirow{2}{*}{$\begin{array}{l}\text { Sample Select } \\
\text { L=Low } \\
\text { M=Medium } \\
\text { H=High }\end{array}$} & \multirow{2}{*}{$\begin{array}{c}\text { Sample } \\
\text { ID }^{\mathrm{a}, \mathrm{b}}\end{array}$} & \multirow{2}{*}{$\begin{array}{l}\text { Gamma } \\
(\mathrm{cpm}) \\
\text { Before }\end{array}$} \\
\hline Area & Northing/X & Easting/Y & & & & \\
\hline SU349 & 2123952 & 525751 & $4-2-2$ & $\overline{\mathbf{M}}$ & 2001S011 & 5056 \\
\hline SU349 & 2123860 & 525721 & $4-2-3$ & & & 2891 \\
\hline SU349 & 2123817 & 525212 & $4-3-1$ & & & 5106 \\
\hline SU349 & 2123956 & 525153 & $4-3-2$ & & & 4838 \\
\hline SU349 & 2123991 & 525507 & $4-3-3$ & $\mathbf{H}$ & 2001S012 & 5488 \\
\hline SU349 & 2122848 & 526146 & Judgmental & -- & $2001 S 025$ & 9000 \\
\hline SU349 & 2122871 & 526205 & Judgmental & -- & 2001S026 & 13000 \\
\hline \multicolumn{7}{|c|}{ Group 2 (Survey Units $1,2,5,6$ ) } \\
\hline SU1256 & 2123912 & 525681 & $1-1-1$ & & & 3868 \\
\hline SU1256 & 2123935 & 525278 & $1-1-2$ & & & 5013 \\
\hline SU1256 & 2123914 & 525000 & $1-1-3$ & $\mathbf{L}$ & $2001 S 013$ & 3049 \\
\hline SU1256 & 2123807 & 525044 & $1-2-1$ & & & 2720 \\
\hline SU1256 & 2123866 & 525086 & $1-2-2$ & & & 3670 \\
\hline SU1256 & 2123899 & 525016 & $1-2-3$ & $\mathbf{M}$ & 2001S014 & 3430 \\
\hline SU1256 & 2123784 & 524905 & $1-3-1$ & $\mathbf{H}$ & 2001S015 & 3753 \\
\hline SU1256 & 2123853 & 524994 & $1-3-2$ & & & 3316 \\
\hline SU1256 & 2123846 & 525394 & $1-3-3$ & & & 2978 \\
\hline SU1256 & 2123908 & 525594 & $2-1-1$ & & & 5000 \\
\hline SU1256 & 2123908 & 525147 & $2-1-2$ & & & 4741 \\
\hline SU1256 & 2123860 & 525284 & $2-1-3$ & $\mathbf{L}$ & 2001S016 & 2951 \\
\hline SU1256 & 2123837 & 525027 & $2-2-1$ & & & 2971 \\
\hline SU1256 & 2123945 & 525260 & $2-2-2$ & & & 4211 \\
\hline SU1256 & 2123791 & 525005 & $2-2-3$ & $\mathbf{M}$ & 2001S017 & 3194 \\
\hline SU1256 & 2123917 & 525309 & $2-3-1$ & $\mathbf{H}$ & 2001S018 & 3464 \\
\hline SU1256 & 2123875 & 525318 & $2-3-2$ & & & 3296 \\
\hline SU1256 & 2123884 & 524991 & $2-3-3$ & & & 3233 \\
\hline SU1256 & 2123888 & 525649 & $3-1-1$ & & & 5060 \\
\hline SU1256 & 2123903 & 525391 & $3-1-2$ & & & 3707 \\
\hline SU1256 & 2123926 & 525046 & $3-1-3$ & $\mathbf{L}$ & 2001S019 & 2845 \\
\hline SU1256 & 2123843 & 525095 & $3-2-1$ & $\mathbf{M}$ & $2001 S 020$ & 3282 \\
\hline SU1256 & 2123868 & 525025 & $3-2-2$ & & & 4218 \\
\hline SU1256 & 2123807 & 525070 & $3-2-3$ & & & 2434 \\
\hline
\end{tabular}




\begin{tabular}{|c|c|c|c|c|c|c|}
\hline \multicolumn{7}{|c|}{$\begin{array}{c}\text { TABLE B-1: } \\
\text { RANKED SET SAMPLING GAMMA MEASUREMENTS } \\
\text { DEFENSE NATIONAL STOCKPILE CENTER NEW HAVEN DEPOT } \\
\text { NEW HAVEN, INDIANA }\end{array}$} \\
\hline \multicolumn{3}{|c|}{ Location } & \multirow{2}{*}{$\begin{array}{c}\text { Ranked Set } \\
\text { Sampling }\end{array}$} & \multirow{2}{*}{$\begin{array}{l}\text { Sample Select } \\
\begin{array}{c}\mathrm{L}=\text { Low } \\
\text { M=Medium } \\
\text { H=High }\end{array}\end{array}$} & \multirow{2}{*}{$\begin{array}{c}\text { Sample } \\
\text { ID }^{\mathrm{a}, \mathrm{b}}\end{array}$} & \multirow{2}{*}{$\begin{array}{c}\text { Gamma } \\
(\mathrm{cpm})\end{array}$} \\
\hline Area & Northing/X & Easting/Y & & & & \\
\hline SU1256 & 2123893 & 525354 & $3-3-1$ & & & 3865 \\
\hline SU1256 & 2123936 & 525306 & $3-3-2$ & $\mathbf{H}$ & $2001 S 021$ & 5275 \\
\hline SU1256 & 2123865 & 525403 & $3-3-3$ & & & 2665 \\
\hline SU1256 & 2123914 & 524975 & $4-1-1$ & $\mathbf{L}$ & $2001 S 022$ & 2860 \\
\hline SU1256 & 2123874 & 525632 & $4-1-2$ & & & 4446 \\
\hline SU1256 & 2123905 & 525725 & $4-1-3$ & & & 3773 \\
\hline SU1256 & 2123902 & 525064 & $4-2-1$ & $\mathbf{M}$ & 2001S023 & 4379 \\
\hline SU1256 & 2123867 & 525113 & $4-2-2$ & & & 4501 \\
\hline SU1256 & 2123920 & 525211 & $4-2-3$ & & & 4320 \\
\hline SU1256 & 2123884 & 525150 & $4-3-1$ & $\mathbf{H}$ & 2001S024 & 4796 \\
\hline SU1256 & 525643 & 2123957 & $4-3-2$ & & & 4564 \\
\hline SU1256 & 525736 & 2123868 & $4-3-3$ & & & 3055 \\
\hline \multicolumn{7}{|c|}{ Group 3 (Survey Unit 210-2-6) } \\
\hline $210-2-6$ & 7.01 & 2.89 & $1-1-1$ & & & 4812 \\
\hline $210-2-6$ & 3.96 & 6.95 & $1-1-2$ & & & 5866 \\
\hline $210-2-6$ & 10.06 & 11.02 & $1-1-3$ & $\mathbf{L}$ & 2001S027 & 4615 \\
\hline $210-2-6$ & 2.43 & 0.63 & $1-2-1$ & $\mathbf{M}$ & 2001S028 & 5130 \\
\hline $210-2-6$ & 8.53 & 4.69 & $1-2-2$ & & & 4668 \\
\hline $210-2-6$ & 5.48 & 8.76 & $1-2-3$ & & & 5315 \\
\hline $210-2-6$ & 11.58 & 1.99 & $1-3-1$ & & & 4297 \\
\hline $210-2-6$ & 0.52 & 6.05 & $1-3-2$ & $\mathbf{H}$ & 2001S029 & 5320 \\
\hline $210-2-6$ & 6.62 & 10.12 & $1-3-3$ & & & 5139 \\
\hline $210-2-6$ & 3.57 & 3.34 & $2-1-1$ & & & 5770 \\
\hline $210-2-6$ & 9.67 & 7.41 & $2-1-2$ & $\mathbf{L}$ & 2001S030 & 4483 \\
\hline $210-2-6$ & 2.05 & 11.47 & $2-1-3$ & & & 5482 \\
\hline $210-2-6$ & 8.15 & 1.08 & $2-2-1$ & & & 4697 \\
\hline $210-2-6$ & 5.10 & 5.15 & $2-2-2$ & & & 5536 \\
\hline $210-2-6$ & 11.20 & 9.21 & $2-2-3$ & $\mathbf{M}$ & 2001S031 & 4730 \\
\hline $210-2-6$ & 1.29 & 2.43 & $2-3-1$ & $\mathbf{H}$ & 2001S032 & 5786 \\
\hline $210-2-6$ & 7.39 & 6.50 & $2-3-2$ & & & 4836 \\
\hline $210-2-6$ & 4.34 & 10.57 & $2-3-3$ & & & 5339 \\
\hline $210-2-6$ & 10.44 & 3.79 & $3-1-1$ & $\mathbf{L}$ & $2001 S 033$ & 4506 \\
\hline $210-2-6$ & 2.81 & 7.86 & $3-1-2$ & & & 5302 \\
\hline
\end{tabular}




\begin{tabular}{|c|c|c|c|c|c|c|}
\hline \multicolumn{7}{|c|}{$\begin{array}{c}\text { TABLE B-1: } \\
\text { RANKED SET SAMPLING GAMMA MEASUREMENTS } \\
\text { DEFENSE NATIONAL STOCKPILE CENTER NEW HAVEN DEPOT } \\
\text { NEW HAVEN, INDIANA }\end{array}$} \\
\hline \multicolumn{3}{|c|}{ Location } & \multirow{2}{*}{$\begin{array}{l}\text { Ranked Set } \\
\text { Sampling }\end{array}$} & \multirow{2}{*}{$\begin{array}{l}\text { Sample Select } \\
\mathbf{L}=\text { Low } \\
\text { M=Medium } \\
\text { H=High }\end{array}$} & \multirow{2}{*}{$\begin{array}{l}\text { Sample } \\
\text { ID }^{a, b}\end{array}$} & \multirow{2}{*}{$\begin{array}{c}\begin{array}{c}\text { Gamma } \\
(\mathrm{cpm})\end{array} \\
\text { Before }\end{array}$} \\
\hline Area & Northing/X & Easting/Y & & & & \\
\hline 210-2-6 & 8.91 & 11.92 & $3-1-3$ & & & 4537 \\
\hline $210-2-6$ & 5.86 & 0.33 & $3-2-1$ & $\mathbf{M}$ & 2001S034 & 5268 \\
\hline $210-2-6$ & 11.96 & 4.39 & $3-2-2$ & & & 4618 \\
\hline $210-2-6$ & 0.33 & 8.46 & $3-2-3$ & & & 5368 \\
\hline $210-2-6$ & 6.43 & 1.68 & $3-3-1$ & & & 5146 \\
\hline $210-2-6$ & 3.38 & 5.75 & $3-3-2$ & $\mathbf{H}$ & $2001 S 035$ & 5341 \\
\hline $210-2-6$ & 9.48 & 9.82 & 3-3-3 & & & 4450 \\
\hline $210-2-6$ & 1.86 & 3.04 & $4-1-1$ & & & 5648 \\
\hline $210-2-6$ & 7.96 & 7.10 & $4-1-2$ & & & 5700 \\
\hline $210-2-6$ & 4.91 & 11.17 & $4-1-3$ & $\mathbf{L}$ & $2001 S 036$ & 4908 \\
\hline $210-2-6$ & 11.01 & 0.78 & $4-2-1$ & & & 4715 \\
\hline $210-2-6$ & 1.10 & 4.84 & $4-2-2$ & & & 5765 \\
\hline $210-2-6$ & 7.20 & 8.91 & $4-2-3$ & $\mathbf{M}$ & 2001S037 & 5059 \\
\hline $210-2-6$ & 4.15 & 2.13 & $4-3-1$ & & & 5407 \\
\hline $210-2-6$ & 10.25 & 6.20 & $4-3-2$ & & & 4488 \\
\hline $210-2-6$ & 2.26 & 10.27 & 4-3-3 & $\mathbf{H}$ & 2001S038 & 5415 \\
\hline
\end{tabular}

${ }^{a}$ Refer to Figures A-5 through A-7.

bSample ID code specifies which location is sampled for a given cycle/set based on the gamma count rate. 


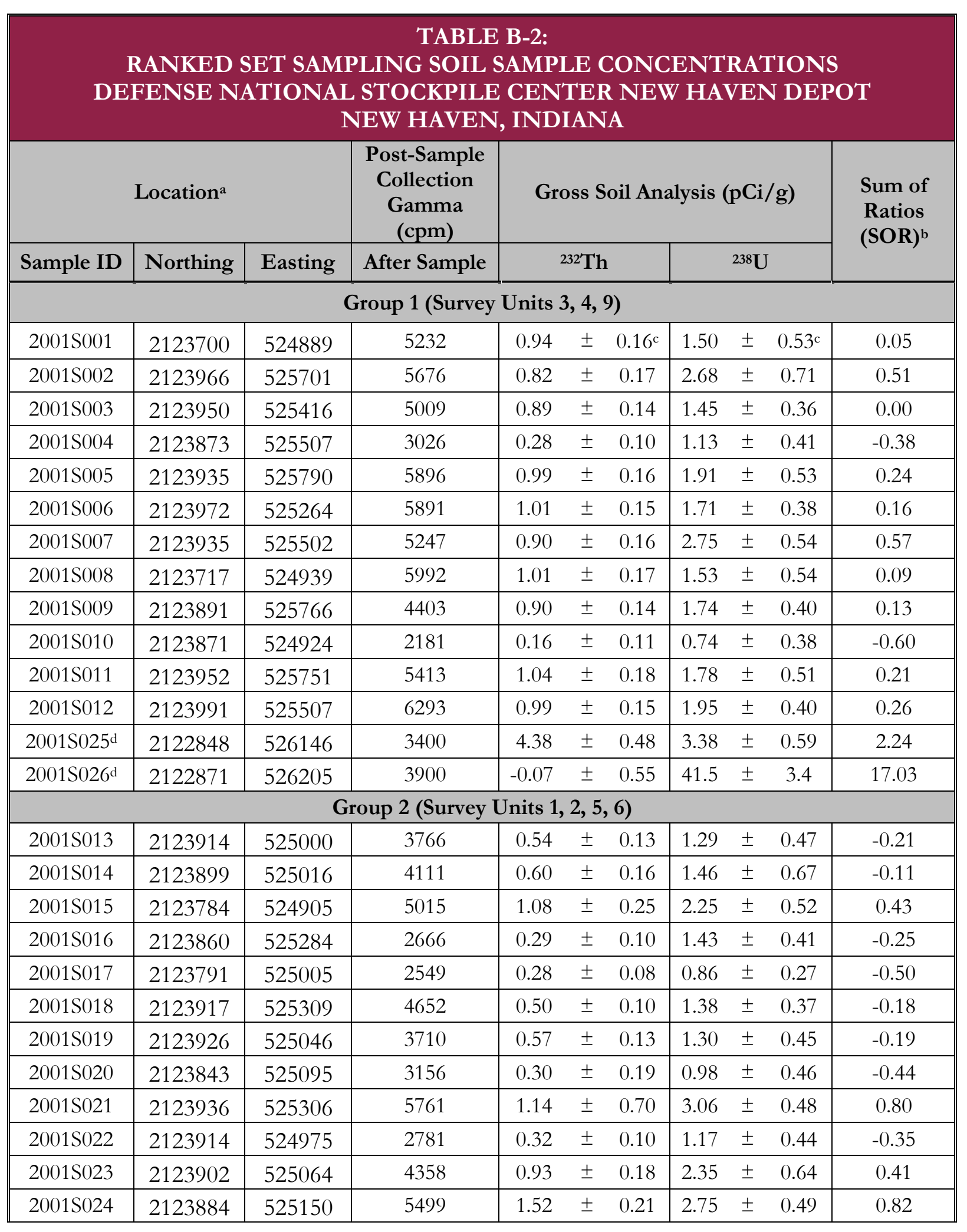




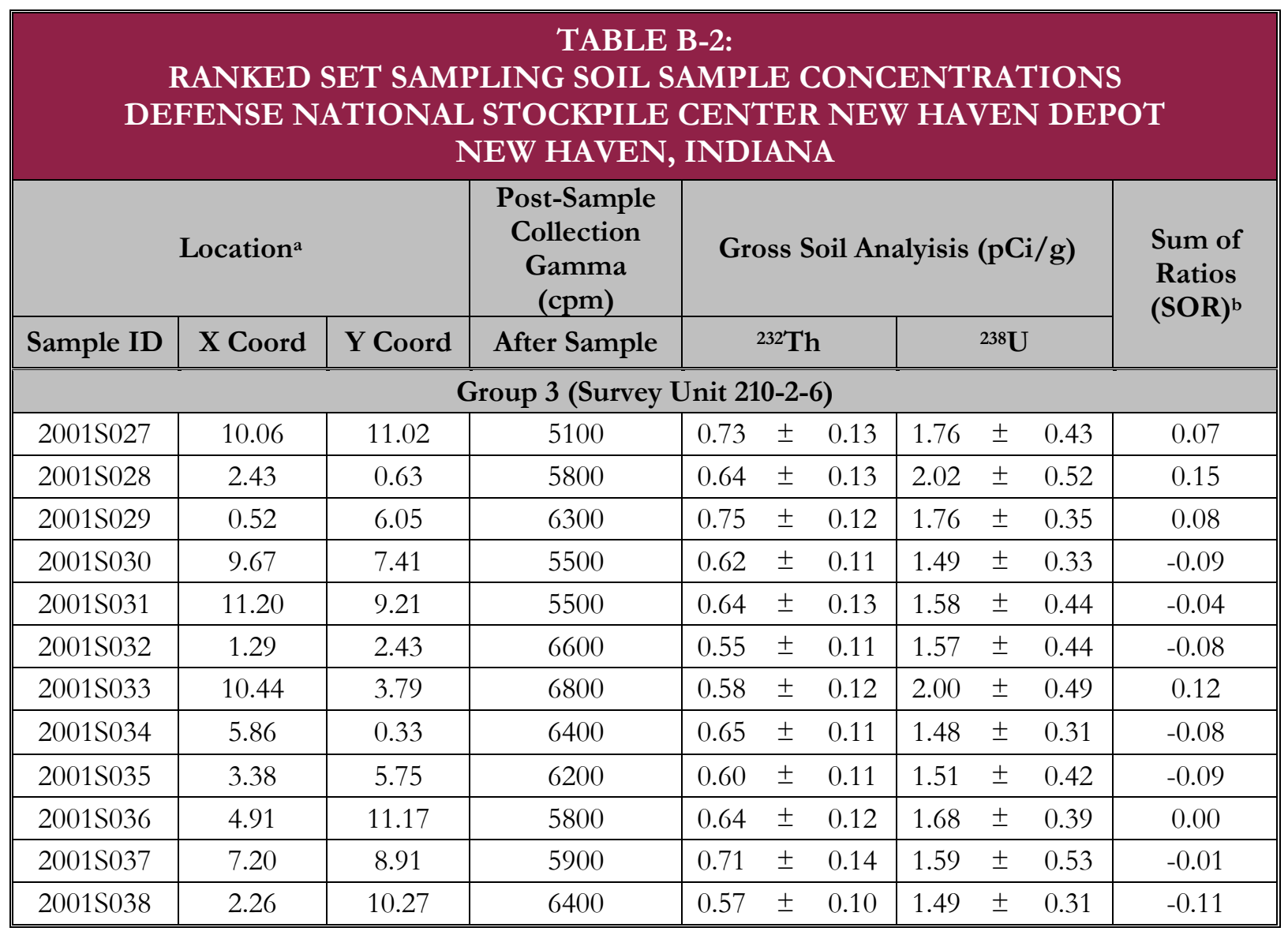

aRefer to Figures A-8 through A-11.

bSum of Ratios (SOR) are reported as the net value of ORISE sample data after the SOR of average background values from Cabrera soil samples had been subtracted.

cUncertainties are total propagated uncertainties, based on the $95 \%$ confidence interval.

dudgemental soil samples from Survey Unit 9. 
TABLE B-3:

STRUCTURAL SURFACE ACTIVITY MEASUREMENTS

DEFENSE NATIONAL STOCKPILE CENTER NEW HAVEN DEPOT

NEW HAVEN, INDIANA

\begin{tabular}{|c|c|c|c|c|c|c|c|c|}
\hline \multirow{3}{*}{ LOCATION $^{\mathrm{a}}$} & \multicolumn{7}{|c|}{ DIRECT DETECTOR MEASUREMENTS } & \multirow{3}{*}{$\begin{array}{l}\text { Meets } \\
\text { DCGL }_{w}\end{array}$} \\
\hline & \multicolumn{3}{|c|}{ VSP Coordinates (m) } & \multirow{2}{*}{ Surface } & \multirow{2}{*}{$\begin{array}{l}\text { Surface } \\
\text { Material }\end{array}$} & \multirow{2}{*}{$\begin{array}{l}\text { Alpha Activity } \\
\left(\mathrm{dpm} / 100 \mathrm{~cm}^{2}\right)\end{array}$} & \multirow{2}{*}{$\begin{array}{c}\text { Alpha + Beta Activity } \\
\left(\mathrm{dpm} / 100 \mathrm{~cm}^{2}\right)\end{array}$} & \\
\hline & Northing/X & Easting/Y & $\mathbf{Z}$ & & & & & \\
\hline
\end{tabular}

SU 210-2-1 (Class 1): Alpha DCGL ${ }_{\mathrm{W}}=38 \mathrm{dpm} / 100 \mathrm{~cm}^{2}$

\begin{tabular}{|c|c|c|c|c|c|c|c|c||}
\hline 1 & 4.67 & 3.04 & NA & Floor & Concrete & 39 & -243 \\
\hline 2 & 7.5 & 1.73 & NA & Floor & Concrete & -1 & -323 \\
\hline 3 & 12.03 & 4.73 & NA & Floor & Concrete & 15 & -357 \\
\hline 4 & 13.26 & 5.92 & NA & Floor & Concrete & -1 & $\leq$ \\
\hline 5 & 14.48 & 5.01 & NA & Floor & Concrete & 7 & -323 & -345 \\
\hline 6 & 16.79 & 4.36 & NA & Floor & Concrete & 15 & $\leq$ \\
\hline
\end{tabular}

SU 210-2-2 (Class 1): Alpha DCGL D $_{\mathrm{W}}=38 \mathrm{dpm} / 100 \mathrm{~cm}^{2}$

\begin{tabular}{|c|c|c|c|c|c|c|c|c|}
\hline 1 & 3.28 & 11.39 & NA & Floor & Concrete & 31 & -291 & $\leq$ \\
\hline 2 & 4.77 & 11.44 & $\mathrm{NA}$ & Floor & Concrete & -25 & -399 & $\leq$ \\
\hline 3 & 1.15 & 3.39 & NA & Floor & Concrete & -25 & -316 & $\leq$ \\
\hline 4 & 4.73 & 2.84 & NA & Floor & Concrete & -33 & -399 & $\leq$ \\
\hline 5 & 1.48 & 1.12 & $\mathrm{NA}$ & Floor & Concrete & 23 & -288 & $\leq$ \\
\hline 6 & 4.23 & 0.89 & $\mathrm{NA}$ & Floor & Concrete & -17 & -240 & $\leq$ \\
\hline
\end{tabular}

SU 210-2-3 (Class 1): Alpha DCGL W $_{\mathrm{W}}=38 \mathrm{dpm} / 100 \mathrm{~cm}^{2}$

\begin{tabular}{|c|c|c|c|c|c|c|c|c||}
\hline 1 & 0.38 & 5.11 & NA & Floor & Concrete & -1 & -65 \\
\hline 2 & 1.53 & 5.05 & NA & Floor & Concrete & 79 & 728 \\
\hline 3 & 6.93 & 3.65 & NA & Floor & Concrete & 174 & 827 \\
\hline 4 & 12.15 & 0.52 & NA & Floor & Concrete & 23 & -116 \\
\hline 5 & 16.48 & 1.33 & NA & Floor & Concrete & 15 & $\leq$ \\
\hline 6 & 18.04 & 1.54 & NA & Floor & Concrete & 7 & -253 & -265 \\
\hline Judgmental & 7.00 & 3.00 & NA & Floor & Concrete & 7 & $\leq 522^{\text {b }}$ \\
\hline
\end{tabular}




\section{TABLE B-3:}

STRUCTURAL SURFACE ACTIVITY MEASUREMENTS

DEFENSE NATIONAL STOCKPILE CENTER NEW HAVEN DEPOT

NEW HAVEN, INDIANA

\begin{tabular}{|c|c|c|c|c|c|c|c|c|}
\hline \multirow{3}{*}{ LOCATION $^{\mathrm{a}}$} & \multicolumn{7}{|c|}{ DIRECT DETECTOR MEASUREMENTS } & \multirow{3}{*}{$\begin{array}{l}\text { Meets } \\
\text { DCGL }_{w}\end{array}$} \\
\hline & \multicolumn{3}{|c|}{ VSP Coordinates (m) } & \multirow{2}{*}{ Surface } & \multirow{2}{*}{$\begin{array}{c}\text { Surface } \\
\text { Material }\end{array}$} & \multirow{2}{*}{$\begin{array}{l}\text { Alpha Activity } \\
\left(\mathrm{dpm} / 100 \mathrm{~cm}^{2}\right)\end{array}$} & \multirow{2}{*}{$\begin{array}{c}\text { Alpha + Beta Activity } \\
\left(\mathrm{dpm} / 100 \mathrm{~cm}^{2}\right)\end{array}$} & \\
\hline & Northing/X & Easting/Y & $\mathrm{Z}$ & & & & & \\
\hline
\end{tabular}

SU 210-2-4 (Class 1): Alpha DCGL $\mathrm{W}_{\mathrm{W}}=38 \mathrm{dpm} / 100 \mathrm{~cm}^{2}$

\begin{tabular}{|c|c|c|c|c|c|c|c|c|}
\hline 1 & 6.15 & 24.65 & 1.33 & North Wall & Wood & -21 & -6 \\
\hline 2 & 17.23 & 24.65 & 1.72 & North Wall & Drywall & 10 & -5 \\
\hline 3 & 0 & 20.1 & 0.52 & West Wall & Brick & $38^{\mathrm{c}}$ & -42 & -25 \\
\hline 4 & 0 & 13.18 & 0.38 & West Wall & Brick & -25 & -39 \\
\hline 5 & 0 & 10.21 & 0.38 & West Wall & Brick & 14 & -125 & $\leq$ \\
\hline 6 & 0 & 9.2 & 0.55 & West Wall & Brick & 30 & $\leq$ \\
\hline
\end{tabular}

SU 210-2-F (Class 3): Alpha DCGL $\mathrm{w}_{\mathrm{w}}=38 \mathrm{dpm} / 100 \mathrm{~cm}^{2}$

\begin{tabular}{|c|c|c|c|c|c|c|c|c|}
\hline 1 & 32.56 & 51.89 & NA & Floor & Concrete & 15 & -103 \\
\hline 2 & 72.14 & 47.86 & NA & Floor & Concrete & 7 & -123 \\
\hline 3 & 71.9 & 13.23 & NA & Floor & Concrete & -1 & -135 & -1 \\
\hline 4 & 51.19 & 6.16 & NA & Floor & Concrete & -1 & $\leq$ \\
\hline 5 & 38.35 & 4.93 & NA & Floor & Concrete & 31 & -126 & -183 \\
\hline 6 & 30.91 & 9.07 & NA & Floor & Concrete & 39 & $>$ \\
\hline
\end{tabular}

SU 210-2-W (Class 3): Alpha DCGL $\mathrm{W}_{\mathrm{W}}=38 \mathrm{dpm} / 100 \mathrm{~cm}^{2}$

\begin{tabular}{|c|c|c|c|c|c|c|c|c||}
\hline 1 & 32.51 & 54.86 & 0.79 & North Wall & Drywall & 10 & -226 \\
\hline 2 & 60.87 & 54.86 & 0.49 & North Wall & Metal & -6 & -210 \\
\hline 3 & 73.15 & 7.39 & 0.73 & East Wall & Brick & -10 & -204 \\
\hline 4 & 29.36 & 0 & 1.93 & South Wall & Drywall & 34 & $\leq$ \\
\hline 5 & 0 & 0.38 & 0.15 & West Wall & Metal & 26 & -175 & -90 \\
\hline 6 & 0 & 4.46 & 0.4 & West Wall & Metal & 10 & $\leq$ \\
\hline
\end{tabular}




\section{TABLE B-3:}

STRUCTURAL SURFACE ACTIVITY MEASUREMENTS

DEFENSE NATIONAL STOCKPILE CENTER NEW HAVEN DEPOT

NEW HAVEN, INDIANA

\begin{tabular}{|c|c|c|c|c|c|c|c|c|}
\hline \multirow{3}{*}{ LOCATION $^{a}$} & \multicolumn{7}{|c|}{ DIRECT DETECTOR MEASUREMENTS } & \multirow{3}{*}{$\begin{array}{l}\text { Meets } \\
\text { DCGL }_{w}\end{array}$} \\
\hline & \multicolumn{3}{|c|}{ VSP Coordinates $(\mathrm{m})$} & \multirow{2}{*}{ Surface } & \multirow{2}{*}{$\begin{array}{l}\text { Surface } \\
\text { Material }\end{array}$} & \multirow{2}{*}{$\begin{array}{l}\text { Alpha Activity } \\
\left(\mathrm{dpm} / 100 \mathrm{~cm}^{2}\right)\end{array}$} & \multirow{2}{*}{$\begin{array}{c}\text { Alpha + Beta Activity } \\
\left(\mathrm{dpm} / 100 \mathrm{~cm}^{2}\right)\end{array}$} & \\
\hline & Northing/X & Easting/Y & $\mathrm{Z}$ & & & & & \\
\hline
\end{tabular}

SU 210-3-F (Class 3): Alpha DCGL $\mathrm{W}_{\mathrm{W}}=38 \mathrm{dpm} / 100 \mathrm{~cm}^{2}$

\begin{tabular}{|c|c|c|c|c|c|c|c|c|}
\hline 1 & 13.99 & 49.06 & NA & Floor & Concrete & 15 & -110 \\
\hline 2 & 39.57 & 45.72 & NA & Floor & Concrete & -1 & -81 \\
\hline 3 & 19.05 & 30.79 & NA & Floor & Concrete & 31 & $\leq$ \\
\hline 4 & 9.81 & 24.66 & NA & Floor & Concrete & 15 & $\leq$ \\
\hline 5 & 20.28 & 24.2 & NA & Floor & Concrete & -17 & 4 \\
\hline 6 & 36.13 & 18.92 & NA & Floor & Concrete & -9 & 1 \\
\hline
\end{tabular}

SU 215-4-F (Class 3): Alpha DCGL $\mathrm{W}_{\mathrm{W}}=38 \mathrm{dpm} / 100 \mathrm{~cm}^{2}$

\begin{tabular}{|c|c|c|c|c|c|c|c|c||}
\hline 1 & 39.02 & 53.86 & NA & Floor & Concrete & 15 & -62 \\
\hline 2 & 56.55 & 47.57 & NA & Floor & Concrete & -9 & -275 \\
\hline 3 & 66.7 & 38.12 & NA & Floor & Concrete & -9 & -69 & -17 \\
\hline 4 & 44.22 & 41.86 & NA & Floor & Concrete & -17 & $\leq$ \\
\hline 5 & 44.57 & 15.52 & NA & Floor & Concrete & -9 & -123 & -9 \\
\hline 6 & 10.41 & 34.37 & NA & Floor & Concrete & -9 & $\leq$ \\
\hline
\end{tabular}

SU 145-F (Class 3): Alpha DCGL $\mathrm{W}_{\mathrm{W}}=100 \mathrm{dpm} / 100 \mathrm{~cm}^{2}$

\begin{tabular}{|c|c|c|c|c|c|c|c|c|}
\hline 1 & 2123544 & 525817 & $\mathrm{NA}$ & Slab & Concrete & 118 & 258 & $>$ \\
\hline 2 & 2123540 & 525811 & $\mathrm{NA}$ & Slab & Concrete & 126 & 147 & $>$ \\
\hline 3 & 2123523 & 525784 & NA & Slab & Concrete & 134 & 268 & $>$ \\
\hline 4 & 2123544 & 525757 & NA & Slab & Concrete & 102 & 265 & $>$ \\
\hline 5 & 2123558 & 525731 & NA & Slab & Concrete & 15 & 4 & $\leq$ \\
\hline 6 & 2123521 & 525699 & $\mathrm{NA}$ & Slab & Concrete & 31 & 109 & $\leq$ \\
\hline
\end{tabular}




\section{TABLE B-3:}

STRUCTURAL SURFACE ACTIVITY MEASUREMENTS

DEFENSE NATIONAL STOCKPILE CENTER NEW HAVEN DEPOT

NEW HAVEN, INDIANA

\begin{tabular}{|c|c|c|c|c|c|c|c|c|}
\hline \multirow{3}{*}{ LOCATION $^{\mathrm{a}}$} & \multicolumn{7}{|c|}{ DIRECT DETECTOR MEASUREMENTS } & \multirow{3}{*}{$\begin{array}{l}\text { Meets } \\
\text { DCGL }_{\mathrm{w}}\end{array}$} \\
\hline & VSP C & ordinates $(r$ & & \multirow{2}{*}{ Surface } & \multirow{2}{*}{$\begin{array}{l}\text { Surface } \\
\text { Material }\end{array}$} & \multirow{2}{*}{$\begin{array}{r}\text { Alpha Activity } \\
\left(\mathrm{dpm} / 100 \mathrm{~cm}^{2}\right)\end{array}$} & \multirow{2}{*}{$\begin{array}{c}\text { Alpha + Beta Activity } \\
\left(\mathrm{dpm} / 100 \mathrm{~cm}^{2}\right)\end{array}$} & \\
\hline & Northing/X & Easting/Y & $\mathrm{Z}$ & & & & & \\
\hline
\end{tabular}

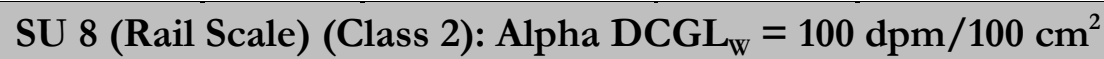

\begin{tabular}{|c|c|c|c|c|c|c|c|c|}
\hline 1 & 2.8 & 2.3 & $\mathrm{NA}$ & Pad & Asphalt & 7 & -256 & $\leq$ \\
\hline 2 & 6.5 & 4.4 & $\mathrm{NA}$ & Pad & Concrete & 71 & -240 & $\leq$ \\
\hline 3 & 10.3 & 0.7 & $\mathrm{NA}$ & Pad & Concrete & 47 & 33 & $\leq$ \\
\hline 4 & 14.1 & 5.5 & NA & Pad & Concrete & 174 & -8 & $>$ \\
\hline 5 & 19 & 3.3 & $\mathrm{NA}$ & Pad & Asphalt & 63 & 373 & $\leq$ \\
\hline 6 & 16.5 & 1.3 & $\mathrm{NA}$ & Pad & Concrete & 39 & 81 & $\leq$ \\
\hline
\end{tabular}

SU 219A (Class 2): Alpha DCGL $\mathrm{W}_{\mathrm{W}}=100 \mathrm{dpm} / 100 \mathrm{~cm}^{2}$

\begin{tabular}{|c|c|c|c|c|c|c|c|c|}
\hline 1 & 1.39 & 1.05 & $\mathrm{NA}$ & East Wall & Wood & -12 & -102 & $\leq$ \\
\hline 2 & 2.1 & 1.49 & $\mathrm{NA}$ & East Wall & Metal & -13 & -302 & $\leq$ \\
\hline 3 & 0.52 & 1.86 & $\mathrm{NA}$ & South Wall & Glass & -13 & -128 & $\leq$ \\
\hline 4 & 2.04 & 0.16 & NA & South Wall & Drywall & -5 & -296 & $\leq$ \\
\hline 5 & 0.24 & 0.38 & $\mathrm{NA}$ & West Wall & Drywall & 2 & -258 & $\leq$ \\
\hline 6 & 1.28 & 0.94 & $\mathrm{NA}$ & Floor & Wood & -5 & 197 & $\leq$ \\
\hline
\end{tabular}

${ }^{a}$ Refer to Figures A-13, A-15, A-16 and A-20 through A-23.

bIndication of elevated beta activity. Survey Plan did not have an established beta contamination DCGLw.

cActivity exceeds the DCGLw when additional significant figures are added; 38 is the rounded down value for the measurement result. 
APPENDIX C

MAJOR INSTRUMENTATION 


\section{APPENDIX C \\ MAJOR INSTRUMENTATION}

The display of a specific product is not to be construed as an endorsement of the product or its manufacturer by the author or his employer.

SCANNING AND MEASUREMENT INSTRUment/DeteCtor COMbinations

\section{$\underline{\text { Gamma }}$}

Victoreen NaI Scintillation Detector Model 489-55, Crystal: $3.2 \mathrm{~cm}$ x $3.8 \mathrm{~cm}$

(Victoreen, Cleveland, $\mathrm{OH}$ )

coupled to:

Ludlum Ratemeter-scaler Model 2221

(Ludlum Measurements, Inc., Sweetwater, TX)

coupled to:

Trimble GeoXH Receiver and Data Logger (Trimble Navigation Limited, Sunnyvale, CA)

\section{Alpha and Alpha plus Beta}

Ludlum Gas Proportional Detector Model 43-68, $126 \mathrm{~cm}^{2}$ active surface area

Ludlum Gas Proportional Detector Model 43-37, $582 \mathrm{~cm}^{2}$ active surface area

(Ludlum Measurements, Inc., Sweetwater, TX)

coupled to:

Ludlum Ratemeter-scaler Model 2221

(Ludlum Measurements, Inc., Sweetwater, TX)coupled to:

Trimble GeoXH Receiver and Data Logger (Trimble Navigation Limited, Sunnyvale, CA)

\section{LABORATORY ANALYTICAL INSTRUMENTATION}

High Purity Extended Range Intrinsic Detector

CANBERRA/Tennelec Model No: ERVDS30-25195

(Canberra, Meriden, CT)

Used in conjunction with:

Lead Shield Model G-11

(Nuclear Lead, Oak Ridge, TN) and

Multichannel Analyzer

Canberra's Apex Gamma Software

Dell Workstation

(Canberra, Meriden, CT) 


\section{LABORATORY ANALYTICAL INSTRUMENTATION (CONTINUED)}

High Purity Extended Range Intrinsic Detector Model No. GMX-45200-5

(AMETEK/ORTEC, Oak Ridge, TN) used in conjunction with:

Lead Shield Model SPG-16-K8

(Nuclear Data)

Multichannel Analyzer

Canberra's Apex Gamma Software

Dell Workstation

(Canberra, Meriden, CT)

High-Purity Germanium Detector

Model GMX-30-P4, 30\% Eff.

(AMETEK/ORTEC, Oak Ridge, TN)

Used in conjunction with:

Lead Shield Model G-16

(Gamma Products, Palos Hills, IL) and

Multichannel Analyzer

Canberra's Apex Gamma Software

Dell Workstation

(Canberra, Meriden, CT) 


\section{APPENDIX D}

\section{SURVEY AND ANALYTICAL PROCEDURES}




\section{APPENDIX D \\ SURVEY AND ANALYTICAL PROCEDURES}

\section{Project Health AND SAFety}

The proposed survey and sampling procedures were evaluated to ensure that any hazards inherent to the procedures themselves were addressed in current job hazard analyses. Additionally, upon arrival on site, a walk-down of the site was performed to identify hazards present and a pre-job integrated safety management checklist was completed and discussed with field personnel. All survey and laboratory activities were conducted in accordance with ORISE health and safety and radiation protection procedures.

\section{CALIBRATION AND QuAlity AssuranCE}

Calibration of all field and laboratory instrumentation was based on standards/sources, traceable to National Institute of Standards and Technology (NIST).

Analytical and field survey activities were conducted in accordance with procedures from the following documents of the Independent Environmental Assessment and Verification Program:

- $\quad$ Survey Procedures Manual (ORISE 2008)

- $\quad$ Laboratory Procedures Manual (ORISE 2009)

- $\quad$ Quality Program Manual (ORAU 2009)

The procedures contained in these manuals were developed to meet the requirements of Department of Energy (DOE) Order 414.1C and the U.S. Nuclear Regulatory Commission Quality Assurance Manual for the Office of Nuclear Material Safety and Safeguards and contain measures to assess processes during their performance.

Quality control procedures include:

- Daily instrument background and check-source measurements to confirm that equipment operation is within acceptable statistical fluctuations. 
- $\quad$ Participation in Mixed Analyte Performance Evaluation Program (MAPEP), NIST Radiochemistry Intercomparison Program (NRIP), and Intercomparison Testing Program (ITP) Laboratory Quality Assurance Programs.

- $\quad$ Training and certification of all individuals performing procedures.

- $\quad$ Periodic internal and external audits

\section{SuRVEY Procedures}

\section{$\underline{\text { Surface Scans }}$}

A NaI scintillation detector was used to scan for elevated gamma radiation. Identification of elevated radiation levels was based on increases in the audible signal from the recording and/or indicating instrument. Additionally, the detectors were coupled to GPS units with data loggers enabling real-time recording in one- or two-second intervals of both geographic position and the gamma count rate. Position and gamma count rate data files were transferred to a computer system, positions differentially corrected, and the results plotted on geo-referenced aerial photographs. Positional accuracy was within 0.5 meters at the $95^{\text {th }}$ percentile.

The scan minimum detectable concentrations for the $\mathrm{NaI}$ scintillation detectors were $2.8 \mathrm{pCi} / \mathrm{g}$ for Th-232, as provided in NUREG-1507, and approximately $4.5 \mathrm{pCi} / \mathrm{g}$ for U-238.

\section{Surface Activity Measurements}

Measurements of total activity levels were performed using gas proportional detectors with portable ratemeter-scalers. Surface activity measurements were performed on floors, lower walls and at locations of elevated direct radiation.

Count rates (cpm), which were integrated over one minute with the detector held in a static position, were converted to activity levels $\left(\mathrm{dpm} / 100 \mathrm{~cm}^{2}\right)$ by dividing the net rate by the total efficiency $\left(\mathrm{e}_{\mathrm{i}} \times \mathrm{e}_{\mathrm{s}}\right)$ and correcting for the active area of the detector. The 2 pi instrument efficiencies $\left(e_{i}\right)$ were as follows: 0.40 to 0.42 for the gas proportional detectors calibrated to Th-230; and 0.48 to 0.49 for the gas proportional detectors calibrated to Tl-204. The release criteria for structures and surfaces at the NHD were based on alpha emitting radionuclides. As a conservative approach, alpha plus beta measurements were collected at the precise alpha measurement locations in an attempt to establish a direct correlation between alpha and alpha plus beta activities. Therefore, the source efficiency 
factors $\left(e_{s}\right)$ were 0.25 for the alpha calibration source and 0.5 for the beta calibration source. The total efficiencies for alpha and alpha plus beta respectively were 0.10 and 0.25 .

Because different building materials (poured concrete, brick, wood, metal, glass, drywall and asphalt) may have different background levels, average background count rates were determined for each material encountered in the surveyed area at a location of similar construction and having no known radiological history. The alpha activity background count rates for the gas proportional detector averaged $3 \mathrm{cpm}$ for metal, glass and drywall; $5 \mathrm{cpm}$ for wood and $6 \mathrm{cpm}$ for poured concrete and asphalt. The alpha plus beta activity background count rates for the gas proportional detector averaged 247 for metal, glass and drywall; $193 \mathrm{cpm}$ for wood and 385 for poured concrete and asphalt. The alpha minimum detectable concentration (MDCs) were $88 \mathrm{dpm} / 100 \mathrm{~cm}^{2}$ for metal, glass and drywall; $106 \mathrm{dpm} / 100 \mathrm{~cm}^{2}$ for wood and $114 \mathrm{dpm} / 100 \mathrm{~cm}^{2}$ for poured concrete and asphalt. The alpha plus beta MDCs were $242 \mathrm{dpm} / 100 \mathrm{~cm}^{2}$ for metal, glass and drywall; 215 $\mathrm{dpm} / 100 \mathrm{~cm}^{2}$ for wood and $299 \mathrm{dpm} / 100 \mathrm{~cm}^{2}$ for poured concrete and asphalt. The physical probe area for the gas proportional detectors was $126 \mathrm{~cm}^{2}$.

\section{Soil Sampling}

Approximately 0.5 to 1 kilogram $(\mathrm{kg})$ of soil was collected at each sample location. Collected samples were placed in a plastic bag, sealed, and labeled in accordance with ORISE survey procedures.

\section{RADIOLOGICAL ANALYSIS}

\section{Gamma Spectroscopy}

Samples of soil were dried, mixed, crushed, and/or homogenized as necessary, and a portion sealed in a 0.5 -liter Marinelli beaker or other appropriate container. The quantity placed in the beaker was chosen to reproduce the calibrated counting geometry. Net material weights were determined and the samples counted using intrinsic germanium detectors coupled to a pulse height analyzer system. Background and Compton stripping, peak search, peak identification, and concentration calculations were performed using the computer capabilities inherent in the analyzer system. All total absorption peaks (TAP) associated with the radionuclides of concern were reviewed for consistency of activity. 
TAPs used for determining the activities of radionuclides of concern and the typical associated MDCs for a one-hour count time were:

\begin{tabular}{|c|c|c|}
\hline \multicolumn{3}{|c|}{ TABLE D-1: MDC DERIVED FROM } \\
\hline \multicolumn{2}{|c|}{ TOTAL ABSORPTION PEAK } \\
\hline Radionuclide & TAP (MeV) & MDC (pCi/g) \\
\hline Th-232 & $0.911 \mathrm{MeV}$ & 0.14 \\
\hline $\mathrm{U}-238$ & $0.0633 \mathrm{MeV}$ & 0.75 \\
\hline
\end{tabular}

Spectra were also reviewed for other identifiable TAPs. The determination of MDCs was derived from the progeny of Th-232 and U-238. Actinium-228 for Th-232 and thorium-234 for U-238. Soil concentration calculations were based on the assumption that actinium-228 and thorium-234 were in equilibrium with their parent isotopes.

\section{DETECTION LIMITS}

Detection limits, referred to as minimum detectable concentrations, were based on $95 \%$ confidence level via NUREG 1507 method; Equation 3-10:

$$
\operatorname{MDC}\left(d p m / 100 \mathrm{~cm}^{2}\right)=\frac{3+4.65 \sqrt{\left(C_{b}\right)}}{K T}
$$

Where:

$$
\begin{array}{ll}
\mathrm{C}_{\mathrm{b}}= & \begin{array}{l}
\text { Average background count in time } \\
\mathrm{K}=
\end{array} \\
\mathrm{T}= & \begin{array}{l}
\text { Constant for detection efficiency and } \\
\text { probe geometry }
\end{array} \\
\mathrm{T}= & \begin{array}{l}
\text { Paired observations of the sample and } \\
\text { blank. }
\end{array}
\end{array}
$$

Because of variations in background levels, measurement efficiencies, and contributions from other radionuclides in samples, the detection limits differ from sample to sample and instrument to instrument. 